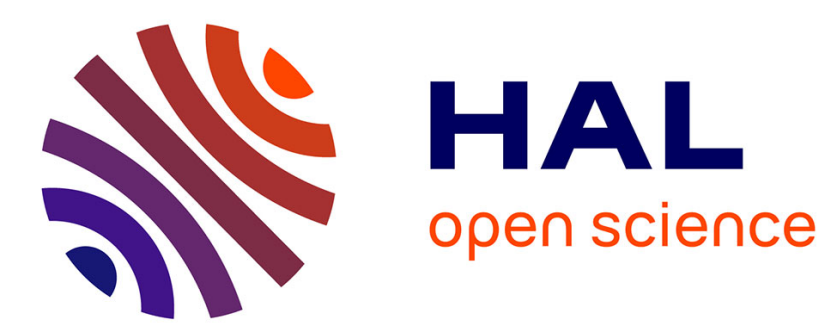

\title{
Barrier layer variability in the western Pacific warm pool from 2000 to 2007
}

C. Bosc, T. Delcroix, C. Maes

\section{To cite this version:}

C. Bosc, T. Delcroix, C. Maes. Barrier layer variability in the western Pacific warm pool from 2000 to 2007. Journal of Geophysical Research. Oceans, 2009, 114, pp.C06023. 10.1029/2008JC005187 . hal-00406884

\section{HAL Id: hal-00406884 \\ https://hal.science/hal-00406884}

Submitted on 6 Jan 2022

HAL is a multi-disciplinary open access archive for the deposit and dissemination of scientific research documents, whether they are published or not. The documents may come from teaching and research institutions in France or abroad, or from public or private research centers.
L'archive ouverte pluridisciplinaire HAL, est destinée au dépôt et à la diffusion de documents scientifiques de niveau recherche, publiés ou non, émanant des établissements d'enseignement et de recherche français ou étrangers, des laboratoires publics ou privés. 


\title{
Barrier layer variability in the western Pacific warm pool from 2000 to 2007
}

\author{
Christelle Bosc, ${ }^{1}$ Thierry Delcroix, ${ }^{1}$ and Christophe Maes ${ }^{2}$ \\ Received 6 November 2008; revised 18 February 2009; accepted 20 April 2009; published 26 June 2009.
}

[1] Major features of the equatorial portion of the western Pacific warm pool (WP) were brought to light through the analysis of an unprecedented collection of temperature and salinity profiles derived from Argo floats from 2000 to 2007. A region of thick $(>15-25 \mathrm{~m})$ and quasi-permanent barrier layers (BLs) was found to occur in a band from $10^{\circ}$ to $20^{\circ}$ longitude to the west of the maximum zonal sea surface salinity gradient $(\partial S / \partial x)$, which occurs at the eastern edge of the WP. In this region, thick BLs and associated maxima $(\partial S / \partial x)$ were displaced eastward (westward) during El Niño (La Niña) over a distance of more than $6000 \mathrm{~km}$. The thickness of the BL in this region is, to the first order, proportional to $\partial S / \partial x$ and quasi-permanently associated with the occurrence of sea surface temperatures warmer than $28-29^{\circ} \mathrm{C}$, which are a good proxy for maximum atmospheric convection for the current Pacific climate. Statistics indicated that a thick BL forms preferentially under low wind conditions, heavy precipitation, eastward advection of low sea surface salinity, zonal current vertical shear, and/or in conjunction with equatorial downwelling Kelvin and Rossby waves (favoring the vertical stretching of the upper water column). None of these processes seemed to dominate the others, indicating that the formation of a thick BL results from a combination of different and complex mechanisms. The fact that a thick BL represents a quasi-permanent feature in the WP signifies that its specific stratification and likely impact on the sea surface temperature balance should be accounted for in coupled models.

Citation: Bosc, C., T. Delcroix, and C. Maes (2009), Barrier layer variability in the western Pacific warm pool from 2000 to 2007, J. Geophys. Res., 114, C06023, doi:10.1029/2008JC005187.

\section{Introduction}

[2] The oceanic Indo-Pacific warm pool is the warming source for the Earth's heat engine. In the Pacific region, the warm pool is located between about $10^{\circ} \mathrm{N}$ and $15^{\circ} \mathrm{S}$ west of $160^{\circ} \mathrm{W}$, and covers an area comparable in size to the surface of the Australian continent. The Pacific warm pool is characterized by sea surface temperatures (SSTs) warmer than $28-29^{\circ} \mathrm{C}$, a sea surface salinity (SSS) fresher than 35 (note that salinity computations are based on the Practical Salinity Scale (PSS-1978), with no units [see Millero, 1993]), an enhanced deep atmospheric convection, heavy precipitation $\left(2-4 \mathrm{~m} \mathrm{a}^{-1}\right)$, and a low wind speed [Tomczak and Godfrey, 1994; K. Wyrtki, Some thoughts about the west Pacific warm pool, paper presented at West Pacific International Meeting and Workshop on TOGA COARE, Institut de Recherche pour le Développement, Nouméa, New Calédonia, 1989]. Several studies have indicated that "weak" oceanic and atmospheric changes in the western Pacific warm pool are important for understanding climate.

\footnotetext{
${ }^{1}$ LEGOS, UMR5566, UPS, CNES, IRD, CNRS, Toulouse, France.

${ }^{2}$ LEGOS, UMR5566, UPS, CNES, IRD, CNRS, Nouméa, New Caledonia.

Copyright 2009 by the American Geophysical Union. 0148-0227/09/2008JC005187
}

For example, model sensitivity studies have revealed that, because of a strong oceanic-atmospheric coupling associated with warm waters in the region, small regional SST changes can lead to severe atmospheric anomalies on a global scale [Palmer and Mansfield, 1984; Hoerling and Kumar, 2003]. Furthermore, oceanic features of the equatorial warm pool have been shown to be tightly related to the development and evolution of ENSO (El Niño Southern Oscillation) events. Of particular interest is the existence of a SSS front located at the eastern edge of the Pacific warm pool that is associated with salinity stratification in the isothermal upper layer.

[3] The eastern edge of the western Pacific warm pool (WP) is characterized by a zonal SSS front in the equatorial band. On average, this front is located near $170^{\circ} \mathrm{E}$ and separates western Pacific waters from relatively saltier central Pacific waters, as revealed by an analysis based on conductivity-temperature-depth (CTD) data collected during oceanographic cruises [Kuroda and McPhaden, 1993; Eldin et al., 1997, 2004; Delcroix and McPhaden, 2002; Maes, 2008]. The SSS gradient surrounding the front can reach amplitudes as large as 1 in $1^{\circ}$ longitude. While displaying weak seasonal variability [Mignot et al., 2007], the front is subjected to large eastward and westward displacements of as much as $8000 \mathrm{~km}$, in synchrony with El Niño and La Niña events [Picaut et al., 1996; Delcroix 
and Picaut, 1998]. The front results from the convergence of high-salinity water masses (advected from the central Pacific) and low-salinity water masses (advected from the western Pacific). Convergence at the eastern edge of the WP, together with the associated zonal SSS front, has led to the development of an advective-reflective conceptual model that accounts for the oscillatory nature of ENSO [Picaut et al., 1997]. Overall, the presence of a SSS front has important consequences for the physics and related biogeochemical features of the equatorial Pacific (see the reviews by Picaut et al. [2001] and Le Borgne et al. [2002]).

[4] The WP is further characterized by a peculiar nearsurface thermohaline structure in the vertical. Here, the temperature mixed layer (typically extending to approximately $80 \mathrm{~m}$ in depth) is not mixed in salinity most of the time, such that the density mixed layer (typically extending to approximately $40 \mathrm{~m}$ depth) is controlled by salt stratification. The layer between the bottom of the density mixed layer and the bottom of the temperature mixed layer has been called the barrier layer [Lukas and Lindstrom, 1991]. The presence of a barrier layer (BL) in the WP has significant thermodynamic and dynamic consequences. As shown in model simulation studies, the BL acts to maintain warm SSTs in the WP by isolating the density mixed layer from entrainment cooling in the bottom of the mixed layer, and favors WP displacements by confining the response to wind forcing in a shallower mixed layer [Maes et al., 1997; Vialard and Delecluse, 1998a, 1998b; Vialard et al., 2002]. Sensitivity studies performed with a coupled model have further suggested that a lack of salinity stratification within the isothermal layer in the WP (in the absence of the BL) may lead to reduced or aborted El Niño events [Maes et al., 2002]. Such sensitivity has been found to be associated with changes in BL thicknesses only on the order of $20-40 \mathrm{~m}$.

[5] Currently, few studies exist that document the BL and its variability in the equatorial Pacific, since doing so requires a long time series of concurrent temperature and salinity profiles with adequate vertical resolution. To our knowledge, the pioneering studies aimed at analyzing tropical Pacific BLs were published by Lindstrom et al. [1987] and Lukas and Lindstrom [1991], who used CTD measurements obtained during two specific WEPOCS cruises carried out west of $155^{\circ} \mathrm{E}$ in July-August 1985 and January-February 1986. In their studies, Lindstrom et al. [1987] and Lukas and Lindstrom [1991] hypothesized that the BL in the WP was caused by the subduction of warm and salty waters from the South Equatorial Current beneath fresh and warm pool waters. In later studies, variability in the BL was documented from CTD measurements obtained during 21 cruises along $165^{\circ} \mathrm{E}$ during 1984-1988 by Delcroix et al. [1992], whose histogram of BL thickness at $165^{\circ} \mathrm{E}$ (with a mean of $24 \mathrm{~m}$ ) was found to be similar to the one obtained at $155^{\circ} \mathrm{E}$. Delcroix et al. [1992] also determined that the BL at $165^{\circ} \mathrm{E}$ was destroyed during episodes of eastward surface flow and equatorial upwelling driven by easterlies. Temperature and salinity time series data collected at discrete depths from the $0-$ $165^{\circ} \mathrm{E}$ mooring site were also utilized to analyze BL variability by Sprintall and McPhaden [1994]. These authors noted that local BL thickness varied with a dominant time scale of 15-25 days and was mainly influenced by eastward advection of low-salinity water moving past the mooring. Other studies based on historical CTD profiles have shed light on the variability of the BL at the ENSO time scale. Ando and McPhaden [1997] analyzed changes in the equatorial Pacific Ocean from 1976 to 1994, and Delcroix and McPhaden [2002] focused on changes in the WP region from 1992 to 2000. The variability of BL thickness was also analyzed in the equatorial band during 1993-2002 [Maes, 2000; Maes et al., 2005]. Maes [2000] and Maes et al. [2005] relied on reconstructed salinity profiles derived from Tropical Atmosphere Ocean project (TAO) temperature measurements and statistical modes [see Maes and Behringer, 2000]. Most recent studies, further discussed below, have suggested a clear relationship between the BL and the occurrence of ENSO events.

[6] While the aforementioned studies provided valuable information regarding the role of the BL, most, if not all, were limited by a rather poor time/space resolution for the computed BL thickness. Only recently have concurrent temperature and salinity profiles, collected by the autonomous floats of the Argo program [Roemmich and Owens, 2000], become available, enabling us to improve the analysis of BL variability. Concurrent profiles were utilized to improve the analysis of BL variability by Sato et al. [2004] and Maes et al. [2006a] in the tropical Pacific, and by Sato et al. [2006] in tropical oceans. By expanding on earlier results and by taking advantage of the capabilities provided by Argo technology, our study sought to analyze BL variability and the mechanisms responsible for WP characteristics from 2000 to 2007 . In particular, we focused on the relationships between the $\mathrm{BL}$ and the zonal SSS front, ENSO features, and hot spots in SST.

[7] Our manuscript is arranged into several sections. Section 2 describes data and methodology. Section 3 presents basic statistics regarding isothermal layer depth (ILD), mixed layer depth (MLD), and barrier layer thickness (BLT); and analyzes the covariability of surface and subsurface thermohaline structures in the WP, with an emphasis on the relationships between the zonal SSS front, warm SST, the BLT, and ENSO. Section 4 analyzes possible mechanisms that influence BL formation and thickness in regards to both local and remote forcing. In section 5 we summarize and discuss the main results.

\section{Data and Processing Methodology}

[8] Our study is based on a collection of temperature and salinity data collected in the equatorial Pacific $\left(120^{\circ} \mathrm{E}\right.$ to $120^{\circ} \mathrm{W}, 5^{\circ} \mathrm{N}$ to $5^{\circ} \mathrm{S}$ ) during the period from 2000 to 2007 . Study data originated from three types of measurements, with Argo floats providing a main data source (Figure 1). Utilized data included $\sim 12,000$ profiles from Argo floats, $\sim 2000$ profiles from CTD data, and $\sim 16,000$ daily averaged data points from complementary surface-only thermosalinographs (TSGs). A time/space distribution of data near the surface (i.e., $10 \mathrm{~m}$ in our case) indicated that Argo measurements were mainly concentrated after 2003. The 2000-2002 Argo data gap was partly filled by adding CTD and surface-only TSG data. Utilized CTD data represents 94 dedicated cruises while the TSG data distribution reflects measurements collected along mean shipping tracks spanning an area from New Caledonia to Japan, crossing the equator from $140^{\circ} \mathrm{E}$ to $170^{\circ} \mathrm{W}$. While combining the 


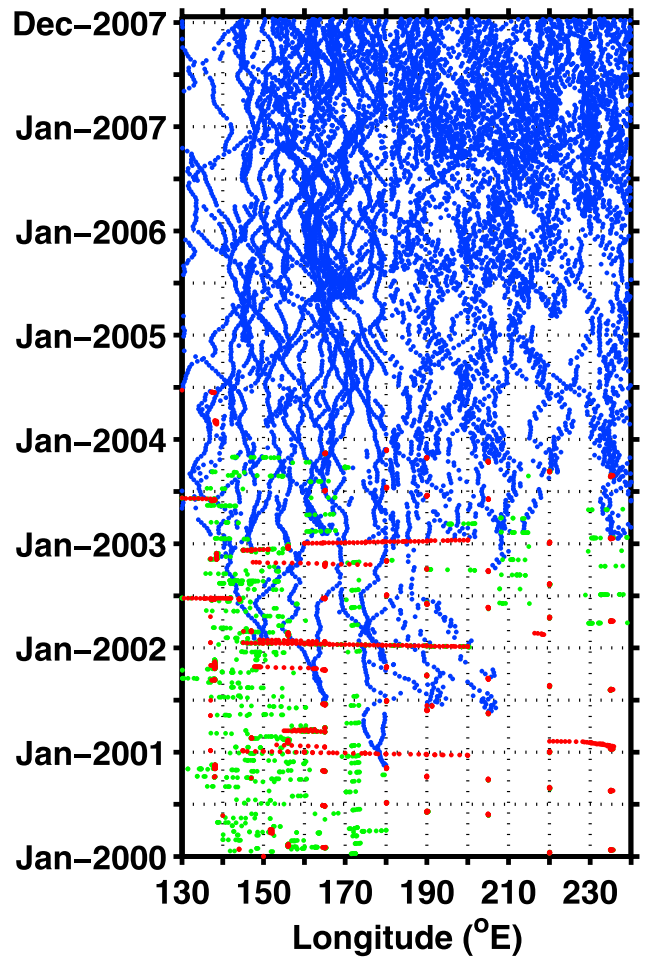

Figure 1. Longitude-time distribution of Argo floats (blue dots), CTD stations (red dots), and TSG (green dots) from $5^{\circ} \mathrm{N}$ to $5^{\circ} \mathrm{S}$.

three sets of measurements did improve the data coverage, Figure 1 clearly indicates that caution is required for the period prior to 2003, especially in the eastern half of the basin. Note that a similar amount of data available at a depth of $10 \mathrm{~m}$ still appears at $100 \mathrm{~m}$ and $200 \mathrm{~m}$ (except for the TSG; not shown).

[9] Argo data profiles are validated on a preliminary basis within the context of operational oceanography via the dedicated routine procedures of the Coriolis Global Data Acquisition Center (GDAC). Only data validated as "good" were downloaded and selected for the study. Delayed mode data were used preferentially when available. We also applied additional tests to filter out spurious data within a depth range from 0 to $200 \mathrm{~m}$. We rejected data with the following profiles: (1) data out of climatic limits $\left(5-35^{\circ} \mathrm{C}\right.$ for temperature and 30-37 for salinity), (2) data with no values in the upper $10 \mathrm{~m}$, (3) data with gaps in excess of $25 \mathrm{~m}$ within the $10-150 \mathrm{~m}$ depth range, (4) data with a density inversion in excess of $0.02 \mathrm{~kg} \mathrm{~m}^{-4}$, and (5) data with an unrealistic vertical temperature gradient (more than $7^{\circ} \mathrm{C}$ in $10 \mathrm{~m}$ ). Using these criteria, approximately $3 \%$ of the original Argo data were discarded. Approximately 12\% of the CTD values were rejected on the basis of similar criteria (mainly because of surface values), and a daily median filter was applied to original 5 min resolution TSG measurements to filter out irrelevant data spikes. Approximately $40 \%$ (92\%) of our selected Argo profiles had a vertical resolution smaller than or equal to 5 (10) $\mathrm{m}$ for the upper $200 \mathrm{~m}$, with an average vertical resolution of $5.9 \mathrm{~m}$. For each Argo profile, temperature and salinity values were then interpolated every $5 \mathrm{~m}$ using a spline function. A similar interpolation was performed for CTD profiles that originally had a higher vertical resolution of $1-2 \mathrm{~m}$. Density was then calculated using interpolated temperature and salinity values.

[10] In the literature, different techniques have been used for estimating the isothermal layer depth (ILD), the density mixed layer depth (MLD), and the derived barrier layer thickness (BLT). The techniques are mainly based on differences or gradient criteria computed from potential temperature and density. For instance, Levitus [1982] defined the ILD as the depth where temperature had a $\Delta \mathrm{T}=0.5^{\circ} \mathrm{C}$ colder than SST $\left(\mathrm{T}_{0}\right)$, and the MLD as the depth where the density $(\rho)$ had increased by $0.125 \mathrm{~kg} \mathrm{~m}^{-3}$ when compared to surface density $\left(\rho_{0}\right)$. Lukas and Lindstrom [1991] defined the thermocline depth as the depth where the temperature gradient $(\partial \mathrm{T} / \partial \mathrm{z})$ exceeded $0.05^{\circ} \mathrm{C} \mathrm{m}^{-1}$, and the MLD as the depth where the density gradient $(\partial \rho / \partial \mathrm{z})$ exceeded $0.01 \mathrm{~kg}$ $\mathrm{m}^{-4}$. A somewhat different technique was proposed by Sprintall and Tomczak [1992], who defined the ILD in terms of a temperature step $\left(\Delta \mathrm{T}=-0.5^{\circ} \mathrm{C}\right)$ from SST and the MLD in terms of a variable density step $(\Delta \rho)$, equivalent to $\Delta \mathrm{T}$, from the sea surface density:

$$
\begin{gathered}
\text { ILD }=\mathrm{Z}\left(\mathrm{T}=\mathrm{T}_{0}+\Delta \mathrm{T}\right) \\
\operatorname{MLD}=\mathrm{Z}\left(\rho=\rho_{0}+\Delta \rho\right) \\
\text { with } \begin{aligned}
\Delta \rho & =\rho\left(\mathrm{T}_{0}+\Delta \mathrm{T}, \mathrm{S}_{0}, \mathrm{P}_{0}\right)-\rho\left(\mathrm{T}_{0}, \mathrm{~S}_{0}, \mathrm{P}_{0}\right) \\
& \approx \partial \rho / \partial \mathrm{T}\left(\mathrm{T}_{0}, \mathrm{~S}_{0}, \mathrm{P}_{0}\right) \cdot \Delta \mathrm{T}
\end{aligned}
\end{gathered}
$$

where $\partial \rho / \partial \mathrm{T}$ is the coefficient of thermal expansion. One advantage of this approach was that any difference between the ILD and the MLD (that is the BLT) was due to salinity stratification. Here the reader should note that the "surface" value $\left(\mathrm{T}_{0}, \mathrm{~S}_{0}\right)$ used in the literature was defined within 1 and $20 \mathrm{~m}$, largely to filter out the effects of diurnal heating on MLD and ILD calculations. Reviews of different MLD and ILD criteria are given by Anderson et al. [1996], Kara et al. [2000], and, more recently, de Boyer Montégut et al. [2004].

[11] With the above considerations in mind, our choice for defining the MLD, the ILD and the surface value was guided by numerous sensitivity tests, quantitative comparisons, visual inspection of Argo profiles, and a consideration of near-surface data availability (see Bosc [2008] for details). We eventually decided to define the ILD and MLD using the Sprintall and Tomczak [1992] technique but changed the temperature threshold to $\Delta \mathrm{T}=-0.2^{\circ} \mathrm{C}$, as in the paper by de Boyer Montégut et al. [2004], with values at $10 \mathrm{~m}$ depth considered as the surface level of reference. Following de Boyer Montégut et al. [2004], the ILD, the MLD, and the resulting BLT were then computed from each vertically interpolated profile before applying any horizontal or temporal averages to individual profiles. For some profiles (2.6\%), MLDs were found significantly deeper (i.e., in excess of $10 \mathrm{~m}$ ) than ILDs (yielding an unrealistic negative BLT), indicating the presence of compensated layers [de Boyer Montégut et al., 2004] which were not analyzed.

[12] Figure 2 shows (as an illustration of ILD, MLD, BLT definitions, and physical descriptions) a longitude-depth 


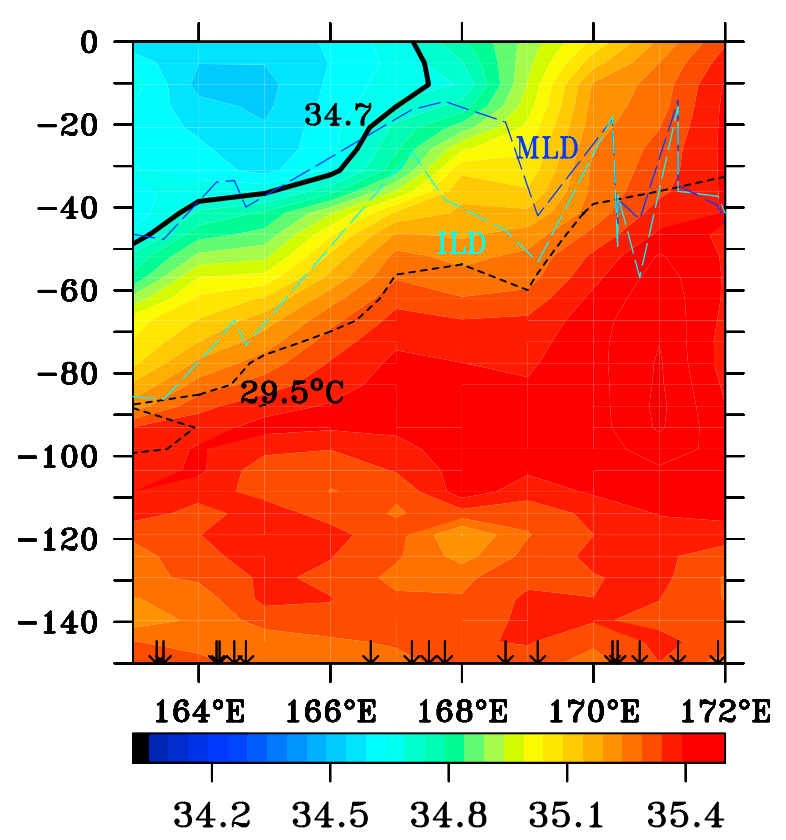

Figure 2. Longitude-depth distribution of salinities averaged within $1.5^{\circ} \mathrm{N}$ to $1.5^{\circ} \mathrm{S}$ during the first half of June 2005, as obtained from Argo floats. The heavy back line denotes the 34.7 isohaline, the dashed black line denotes the $29.5^{\circ} \mathrm{C}$ isotherm, the dashed blue line denotes the mixed layer depth (MLD), and the dashed green line denotes the isothermal layer depth (ILD). The difference between the ILD and the MLD denotes the barrier layer thickness. Note that the black arrows at the bottom of Figure 2 mark the positions of Argo floats.

distribution of salinity for a $10^{\circ}$ longitude section collected in the equatorial band $\left(163-172^{\circ} \mathrm{E}\right)$ during the first half of June 2005 . The $10^{\circ}$ longitude section was chosen since it was obtained from Argo floats designed with enhanced vertical resolution in the upper $250 \mathrm{~m}$ (see the Frontalis 3 cruise report by Maes et al. [2006b]). In Figure 2, we clearly noted the presence of a sharp zonal SSS front from $168^{\circ} \mathrm{E}$ to $171^{\circ} \mathrm{E}$ and, to the west, a MLD on the order of $30-40 \mathrm{~m}$, an ILD of 40-80 m, and a BLT of approximately $10-40 \mathrm{~m}$. Interestingly, the MLD and the ILD tended to converge to the east of the zonal SSS front, featuring the progressive eastward disappearance of the barrier layer. The apparent connection between the zonal SSS front and the occurrence of a barrier layer to the west will be discussed below for the entire 2000-2007 period.

[13] Estimates of the MLD, the ILD, and the BLT derived from individual profiles were interpolated onto a regular grid of $5^{\circ}$ longitude by $1^{\circ}$ latitude by two weeks, covering the $5^{\circ} \mathrm{N}$ to $5^{\circ} \mathrm{S}$ and $120^{\circ} \mathrm{E}$ to $120^{\circ} \mathrm{W}$ region for the period of 2000-2007. Additional data and/or derived quantities are used in the following discussion and include (1) the 0/200 dbar dynamic height anomalies calculated from all individual temperature and salinity profiles; (2) the $1^{\circ}$ longitude by $0.5^{\circ}$ latitude by one week altimeter-derived sea level anomalies (SLA), related zonal geostrophic current anomalies $\left(\mathrm{u}_{\mathrm{g}}^{\prime}\right)$, and the contribution of equatorial Kelvin and Rossby waves to these SLA and $\mathrm{u}_{\mathrm{g}}^{\prime}$ [see Bosc and Delcroix, 2008]; (3) the monthly observed zonal currents at the TAO mooring sites along the equator [McPhaden, 1995]; (4) the $2.5^{\circ}$ longitude by $2.5^{\circ}$ latitude monthly estimates of precipitation from the Global Precipitation Climatology Project (GPCP) [Adler et al., 2003]; and (5) the $1 / 4^{\circ}$ longitude by $1 / 4^{\circ}$ latitude by one week Quikscat wind product [Bentamy et al., 1999]. All of these variables (except for the TAO currents) were reprocessed onto the same $5^{\circ}$ longitude by $1^{\circ}$ latitude by two week gridded fields as for the ILD, the MLD and the BLT by using either an averaging technique or a simple linear interpolation.

\section{Observed Thermohaline Variability}

\subsection{Basic Statistics of BL Thickness}

[14] Figure 3 shows percentages of occurrences for BLs thicker than 10,20 , and $30 \mathrm{~m}$, as computed in $5^{\circ}$ longitude boxes for all 2000-2007 individual profiles located from $2^{\circ} \mathrm{N}$ to $2^{\circ} \mathrm{S}$. Note that the statistics are based on a number of profiles in each box ranging from 40 to 510 . Figure 3 reveals that BLs thicker than $10 \mathrm{~m}$ are frequent $(60-75 \%$ of the time) between approximately $140^{\circ} \mathrm{E}$ and $160^{\circ} \mathrm{E}$ and appear less frequently while moving to the east. Similarly, BLs thicker than 20 (30) $\mathrm{m}$ are frequent from $140^{\circ} \mathrm{E}$ to $160^{\circ} \mathrm{E}$, appear approximately $50 \%(30 \%)$ of the time, and display a percentage of occurrence that diminishes almost linearly to the east while reaching less than $10 \%$ near

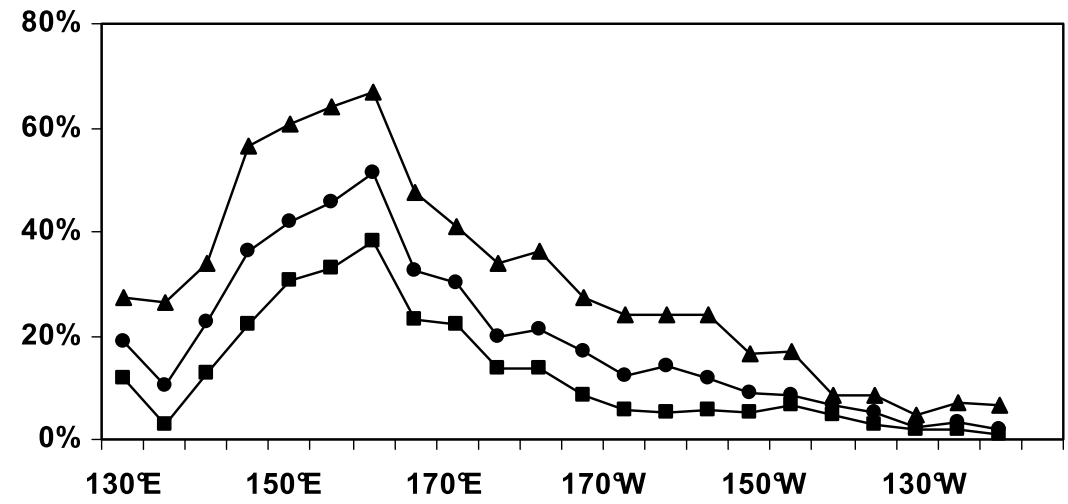

Figure 3. Percentage of individual temperature and salinity profiles with barrier layers thicker than 10 (triangles), 20 (circles), and $30 \mathrm{~m}$ (squares), as computed from Argo floats within $5^{\circ}$ longitude zonal boxes for the $2^{\circ} \mathrm{S}$ to $2^{\circ} \mathrm{N}$ region during the period of 2000-2007. 

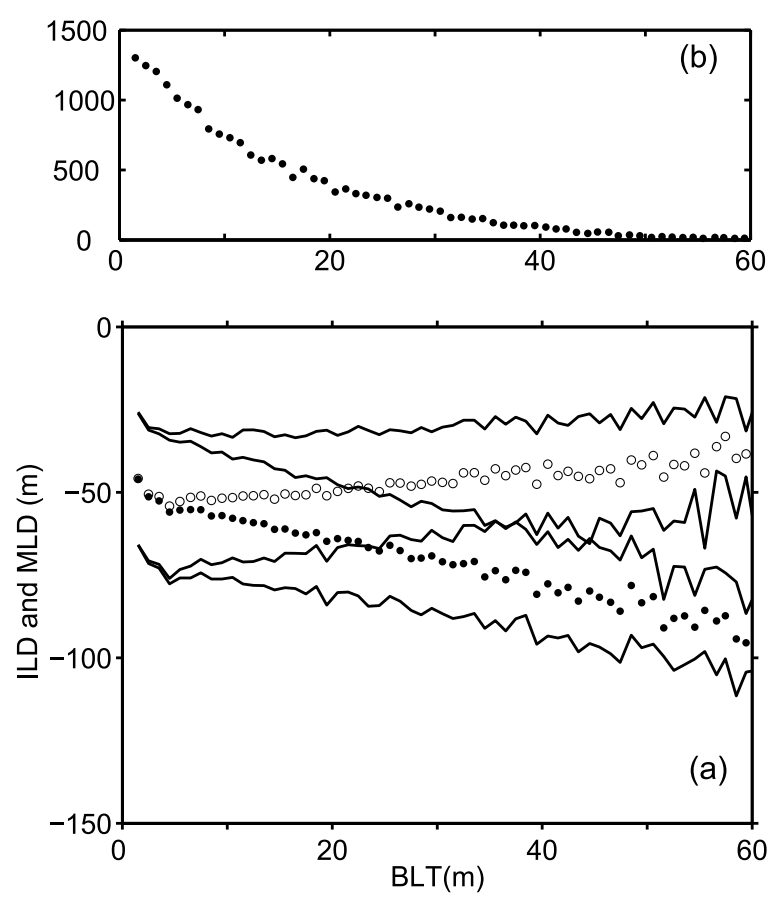

Figure 4. (a) Bin-averaged mixed layer depth (open circles, $\mathrm{m}$ ) and isothermal layer depth (solid circles, m), as a function of barrier layer thickness (BLT) (m), for $1 \mathrm{~m}$ BLT bins. Also shown are the corresponding \pm 1 standard deviation curves (black lines). (b) Population of the bins. All values were derived in the region from $120^{\circ} \mathrm{E}$ to $120^{\circ} \mathrm{W}$ and $5^{\circ} \mathrm{S}$ to $5^{\circ} \mathrm{N}$ during the period from 2000 to 2007 .

$110^{\circ} \mathrm{W}$ (also note the abrupt drop westward of $140^{\circ} \mathrm{E}$ ). The percentages of occurrence are consistent with the results of de Boyer Montégut et al. [2007] indicating that significant BLs are present at least 10 months $\mathrm{a}^{-1}$ in the WP during a mean annual cycle. By using Argo or higher-resolution CTD profiles, independently, similar statistics (not shown) are obtained, justifying the relevance, a posteriori, of Argo data for estimating BLT.

[15] To identify the respective contribution of the MLD and the ILD to BLT changes, the mean and standard deviation of the ILD (and the MLD) were calculated from gridded fields by considering all of the values for the ILD (and the MLD) within each BLT bin of $1 \mathrm{~m}$. In the $2^{\circ} \mathrm{N}$ to $2^{\circ} \mathrm{S}$ equatorial band, Figure $4 \mathrm{a}$ indicates that a thickening of the BL results, on average, from both a deepening of the ILD and a shoaling of the MLD (and vice versa for a thinning of the BL). Figure $4 \mathrm{~b}$ shows that the region where the BLT exceeds approximately $40 \mathrm{~m}$ represents a rather small fraction of measurements, and should thus be viewed with caution (this comment applies to Figures 8 and 9 below). Regression coefficients were $R_{c}=0.7$ and $R_{c}=$ -0.3 for changes in the ILD versus the BLT and for those in the MLD versus the BLT (e.g., a $20 \mathrm{~m}$ thickening of the BL in Figure $4 \mathrm{a}$ results from a $14 \mathrm{~m}$ deepening of the ILD and a $6 \mathrm{~m}$ shoaling of the MLD), respectively. These results indicate that the BLT in the WP region is, on average, roughly twice as affected by changes in the ILD than in the MLD. However, a differential deepening of both the MLD and the ILD could also result in a thickening of the BLT, and will be explored in section 3.2.

[16] The mean and standard deviation of the BLT, between $2^{\circ} \mathrm{N}$ and $2^{\circ} \mathrm{S}$ for the period from 2000 to 2007 , are shown in Figure 5. The mean BLT had a maximum (22 \pm $10 \mathrm{~m}$ ) between $160^{\circ} \mathrm{E}$ and $170^{\circ} \mathrm{E}$, and decreased both to the west (to reach $7 \pm 4 \mathrm{~m}$ at $130^{\circ} \mathrm{E}$ ) and to the east (to reach less than $4 \pm 4 \mathrm{~m}$ at $120^{\circ} \mathrm{W}$ ). A maximum BLT appeared at approximately $5-10^{\circ}$ longitude to the west of the mean position of the maximum zonal SSS gradient $(\partial S / \partial x$, calculated using a centered differencing scheme; the star symbol in Figure 5) located near $167^{\circ} \mathrm{E}$. The standard deviation of the BLT ranged between 4 and $12 \mathrm{~m}$, with a maximum value in the western central equatorial Pacific nearby the mean position of the zonal SSS front.

\subsection{Relationship Between SST, SSS, and Displacements of the Zonal SSS Front}

[17] Figure 6 shows the longitude-time diagrams for SSS, $\mathrm{SST}, \partial S / \partial x$, and BLT, averaged within the $2^{\circ} \mathrm{N}$ to $2^{\circ} \mathrm{S}$ band. Figure $6 \mathrm{a}$ exhibits the well-marked contrast between the low-salinity waters of the western equatorial Pacific and the relatively high salinity waters of the central equatorial Pacific. Such a contrast has been documented for earlier time periods, relying on more sparsely distributed data [Delcroix and Picaut, 1998; Vialard and Delecluse, 1998b; Picaut et al., 2001; Maes et al., 2006a]. Figure 6 also reveals that the common boundary between the two different SSS regions can be adequately delimited by the position of the maximum zonal salinity gradient $(\partial S / \partial x$; the black line in Figure 6a). Statistical analyses based on correlation coefficients and ratios of zonal displacements indicate that the boundary is the location of the 34.7 isohaline (as compared with other tested isohalines), which agrees best with the location of maximum $\partial S / \partial x$ (the correlation coefficient between longitudes is $\mathrm{R}=0.87$ ). This finding differs slightly from pre-2000 investigations that, for the most part, used the 35 isohaline to delimit the eastern edge of the WP, likely because the WP was saltier in past decades than today [Delcroix et al., 2007]. In the following discussion we use the maximum $\partial S / \partial x$ to denote the eastern edge of the WP.

[18] In contrast to the SSS in Figure 6a, SST in Figure 6b nearly linearly increases from the eastern to the western equatorial Pacific, with the absence of a well-marked zonal SST front at the eastern edge of the WP. A remarkable

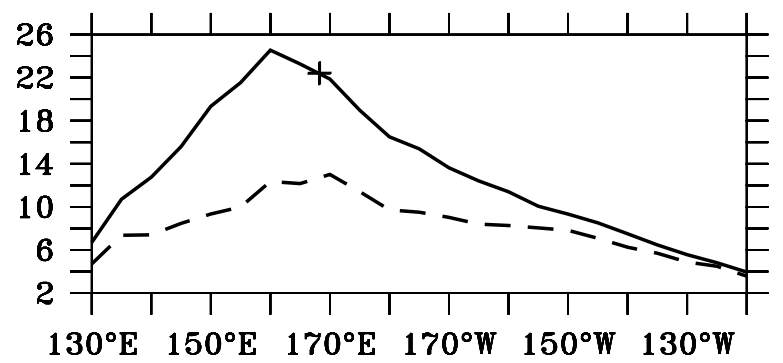

Figure 5. Mean (black line) and standard deviation (dashed line) of the $2^{\circ} \mathrm{N}$ to $2^{\circ} \mathrm{S}$ averaged barrier layer thicknesses (m) for the period from 2000 to 2007. The cross near $167^{\circ} \mathrm{E}$ represents the mean position of the maximum zonal gradient in $\mathrm{SSS}(\partial S / \partial x)$. 


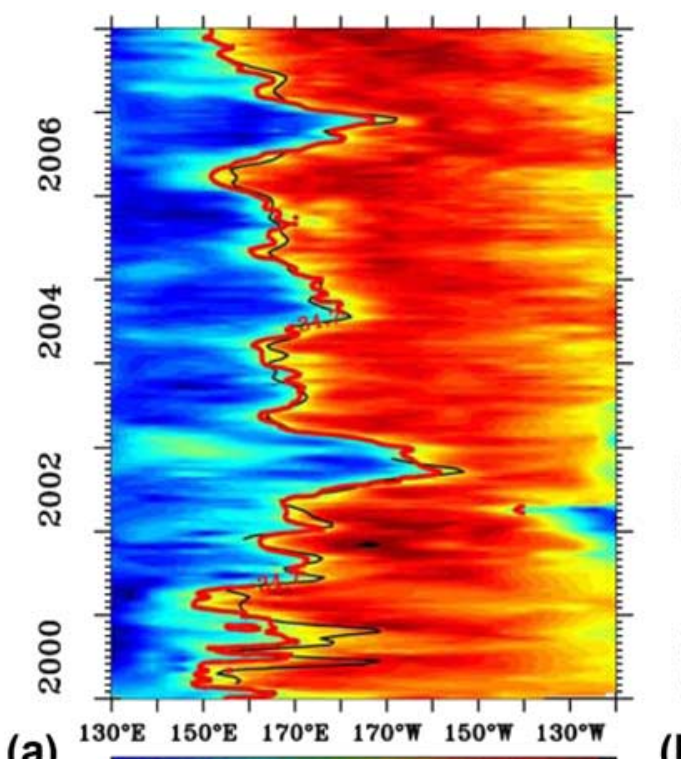

(a)
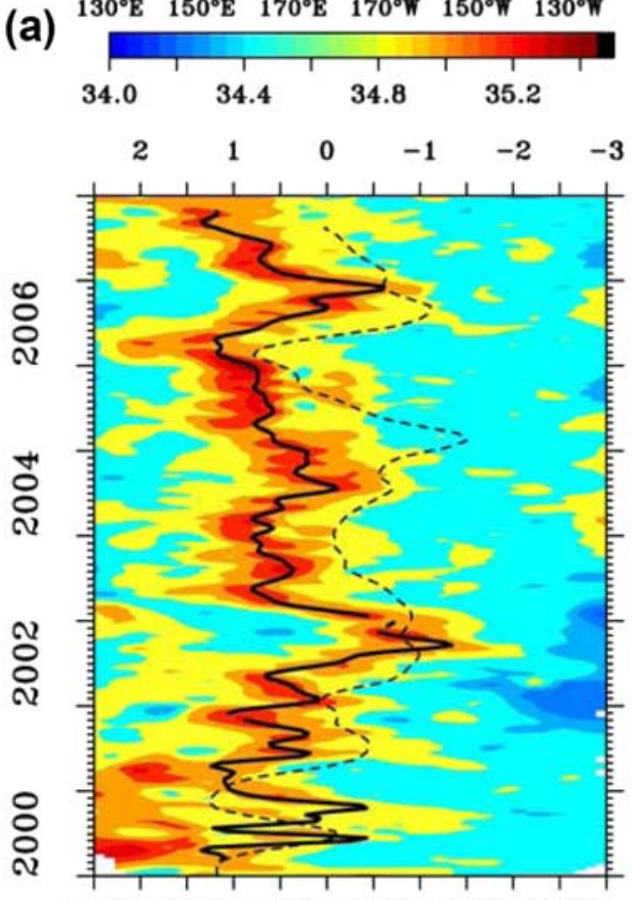

(c)
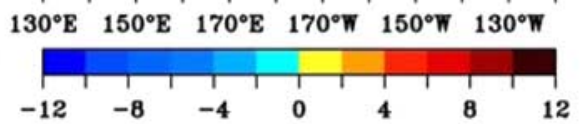
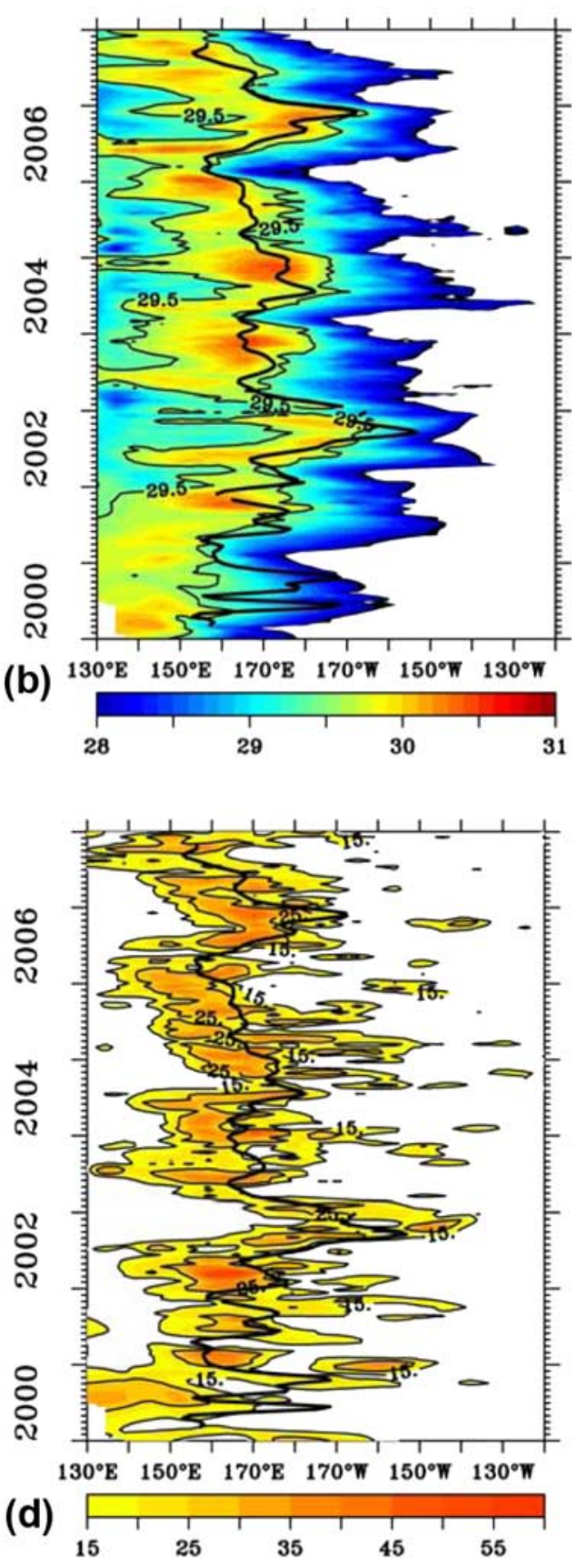

Figure 6. Longitude-time distribution of $2^{\circ} \mathrm{N}$ to $2^{\circ} \mathrm{S}$ averaged (a) SSS, (b) SST, (c) zonal SSS gradient $(\partial S / \partial x)$, and (d) barrier layer thickness. Heavy black lines represent the maximum $\partial S / \partial x$ for Figures $6 a-$ $6 \mathrm{~d}$. The red line in Figure 6a denotes the 34.7 isohaline. The thin black line in Figure $6 \mathrm{~b}$ denotes the $29.5^{\circ} \mathrm{C}$ isotherm. The dashed line in Figure $6 \mathrm{c}$ denotes the Southern Oscillation Index scaled in reverse order on the upper horizontal axis. Note that values in excess of $28^{\circ} \mathrm{C}$ and $15 \mathrm{~m}$ are only reported in Figures $6 \mathrm{~b}$ and $6 \mathrm{~d}$, respectively. Units are ${ }^{\circ} \mathrm{C}$ for Figure $6 \mathrm{~b}, 10^{-7} \mathrm{~m}^{-1}$ for Figure $6 \mathrm{c}$, and $\mathrm{m}$ for Figure $6 \mathrm{~d}$.

feature for SST is that the location of the warmest waters $\left(>29.5^{\circ} \mathrm{C}\right)$ extends $10-20^{\circ}$ in longitude west of the moving eastern edge of the WP. A similar zonal extension for the warmest waters associated with the eastern edge of the WP was documented by Maes et al. [2004, Figure 3] during 1992-2001, on the basis of reconstructed SSSs estimated using an indirect approach, and by Maes et al. [2006a, Figure 2] during 2002-2004 (note that these authors used the 34.4 or 34.6 isohalines to denote the eastern edge). Our analysis using Argo-derived SSSs and SSTs indicates that the occurrence of the warmest SST is a permanent and robust feature that appears tightly linked to, and west of, the moving zonal SSS front at the eastern edge of the WP. Therefore, the frontal region appears to be a favorable location for the formation of "hot spots" in SST [see Waliser, 1996]. Related climatic implications for this feature are discussed in section 3.1. 

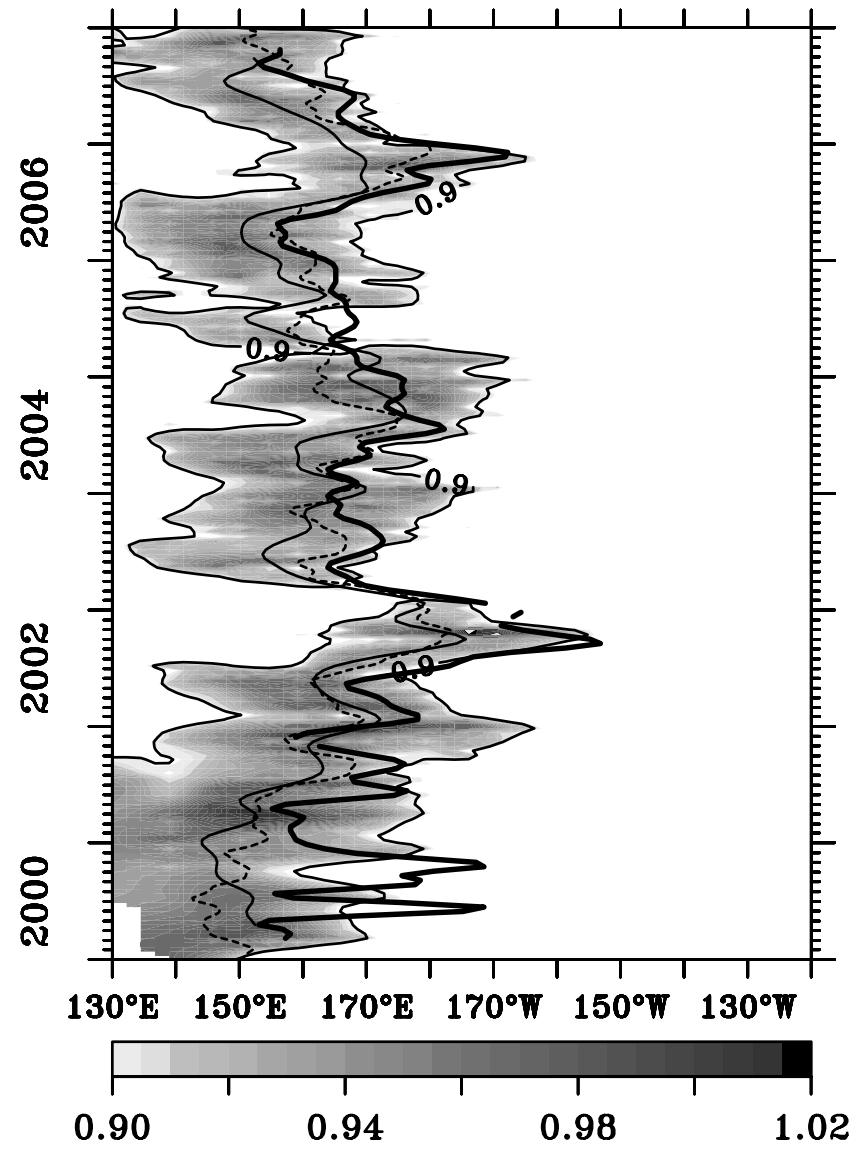

Figure 7. Longitude-time distribution of $2^{\circ} \mathrm{N}$ to $2^{\circ} \mathrm{S}$ averaged for 0/200 dbar dynamic height anomalies; only values in excess of 0.9 dyn $\mathrm{m}$ are reported. The dashed line is the location for the maximum $0 / 200 \mathrm{dbar}$ dynamic height anomalies, the heavy black line represents the maximum $\partial S / \partial x$ (as in Figure 6), and the thin black line is the convergence zone of hypothetical drifters transported by the zonal surface current (see text for details).

[19] Figure $6 \mathrm{c}$ shows the longitude-time plot of $2^{\circ} \mathrm{N}$ to $2^{\circ} \mathrm{S}$ averaged $\partial S / \partial x$, together with the longitudinal position of its maximum, and the Southern Oscillation Index (SOI). Figure 6c reveals that the eastern edge of the WP was displaced eastward during El Niño years (2002, 2004, and 2006) and westward during La Niña years (2000-2001, 2007). To identify the causes of these zonal displacements, we used a technique described by Gill [1983] and applied by Picaut and Delcroix [1995] for altimeter-derived currents. Specifically, we computed the trajectories of hypothetical drifters transported by the $2^{\circ} \mathrm{N}$ to $2^{\circ} \mathrm{S}$ zonal surface current $\left(\mathrm{u}=\mathrm{U}+\mathrm{u}^{\prime}\right)$, for which current anomalies $\left(\mathrm{u}^{\prime}\right)$ were derived from Bosc and Delcroix [2008] and mean current fields (U) were derived from Sudre and Morrow [2008]. A group of hypothetical drifters were launched at $10-20^{\circ}$ longitude east and west of the eastern edge of the WP at 1year intervals, every year, then displaced by the zonal current. As expected, the drifter trajectories all converged after approximately 1 year or less (not shown), and the resulting dynamical convergence zone was found to be displaced in parallel to the maximum $\partial S / \partial x$ (Figure 7).
Therefore, our results confirm earlier results (see Picaut et al. [2001] for a review) indicating that zonal advection mainly accounts for the zonal displacements of the WP during the period from 2000 to 2007 .

[20] The convergence of the hypothetical surface drifters at the eastern edge of the warm pool and the expected mass convergence can be further inferred by looking at the variability of 0/200 dbar dynamic height anomalies (Figure 7). Such a convergence shows up as a zonal band of roughly $20^{\circ}$ in longitude for which the anomalies exceed 0.9 dyn $\mathrm{m}$. The area moves east and west in phase with the maximum $\partial S / \partial x$, in agreement with model results obtained for the period of 1986-1994 [Picaut et al., 2001]. The related mass convergence accounts for the relative maximum of surface dynamic height anomalies located between approximately $160-170^{\circ} \mathrm{E}$ in climatological data, as indicated in earlier publications [Wyrtki, 1984; McPhaden et al., 1998; Le Borgne et al., 2002]. These results suggest that, when SSS measurements (and therefore $\partial S / \partial x$ ) are unavailable, the use of absolute sea level (derived from GRACE-type and Jason satellites) can be used as a substitute for detecting the eastern edge of the warm pool and the associated BLT.

\subsection{Relations Between SSS Front, Warm SST, and BLT}

[21] To better define the relationship between the SSS front and the BLT, as illustrated in Figures 2 and 5, Figure $6 \mathrm{~d}$ shows the longitude-time plots of the $2^{\circ} \mathrm{N}$ to $2^{\circ} \mathrm{S}$ averaged BLT. Interestingly, Figure $6 \mathrm{~d}$ indicates that BLs thicker than $15 \mathrm{~m}$ are only and always present (except for 2 to 3 months in 2001) in a zonal band extending from approximately $10^{\circ}$ longitude to the east and $20^{\circ}$ longitude to the west of the moving front position, whereas a BL thicker than $25 \mathrm{~m}$ mainly appears to the west of the front. To further illustrate this relationship, Figure 8 presents the mean and standard deviation of $\partial S / \partial x$ as a function of the BLT. The mean and standard deviations of $\partial S / \partial x$ were calculated by considering all the values of $\partial S / \partial x$ within each BLT bin of $1 \mathrm{~m}$, for the $2^{\circ} \mathrm{N}$ to $2^{\circ} \mathrm{S}$ equatorial band during 2000-2007. Figure $8 \mathrm{a}$ reveals, to a first approximation, that the BLT within 10 and $40 \mathrm{~m}$ is almost linearly related to the strength of the zonal SSS gradient $\left(\mathrm{BLT}=16.5 \times 10^{7} \partial S / \partial x+5 \times 10^{7}\right)$. BLs thicker than $40 \mathrm{~m}$ appear only for a $\partial S / \partial x$ in excess of approximately $2 \times 10^{-7} \mathrm{~m}^{-1}$ with a standard deviation for $\partial S / \partial x$ of similar magnitude. The maximum $\partial S / \partial x$, which is well suited to characterize the eastern edge of the warm pool, may therefore be viewed as an additional source of information regarding the expected thickness of the $\mathrm{BL}$, a feature that cannot be obtained by using any particular isohaline (such as the 34.7). As a consequence, we expect that the combination of in situ and future satellite-derived SSS measurements [e.g., Kerr et al., 2001] will be quite useful, not only for locating the SSS front and the derived BL location, but also for providing estimates of the thickness of the BL in the WP.

[22] A visual comparison between Figures $6 \mathrm{~b}$ and $6 \mathrm{~d}$ reveals the outstanding time/space coincidence between the warmest $\left(>29.5^{\circ} \mathrm{C}\right) \mathrm{SST}$ and the occurrence of the thickest $(>20 \mathrm{~m}) \mathrm{BL}$. To further document this relationship, Figure $8 \mathrm{~b}$ presents related data in the form of the mean and standard deviation of SST as a function of BLT. The mean SST curve roughly delimits two specific regions. In the first 

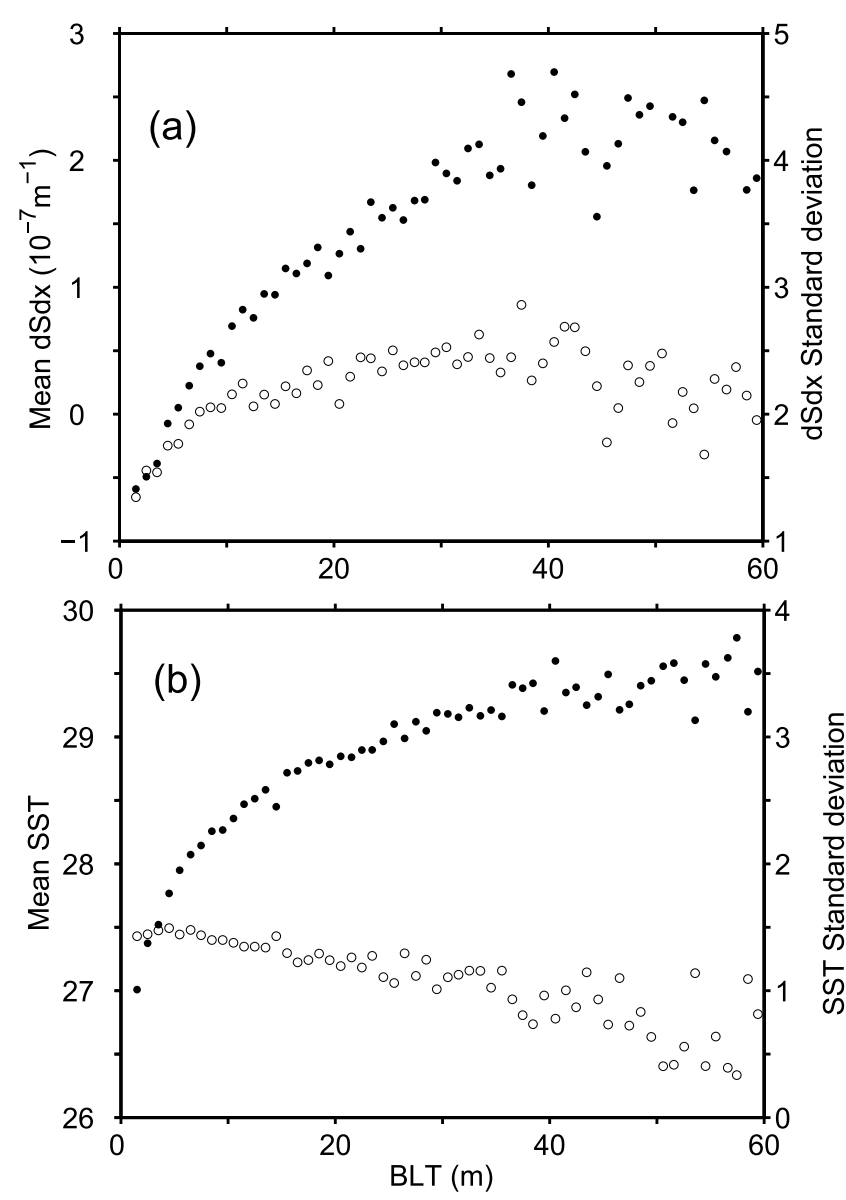

Figure 8. Bin-averaged (a) zonal salinity gradient (solid circles, $10^{-7} \mathrm{~m}^{-1}$ ) and (b) SST (solid circles, ${ }^{\circ} \mathrm{C}$ ), as a function of barrier layer thickness (BLT) (m), for $1 \mathrm{~m} \mathrm{BLT}$ bins. Also shown are the corresponding standard deviations (open circles) scaled on the right vertical axis. The population of the bins is shown in Figure $4 \mathrm{~b}$.

region, the SST increases from roughly $27-29^{\circ} \mathrm{C}$ while the BLT increases from 0 to $\sim 20 \mathrm{~m}$. In the second region, the SST exceeds $29^{\circ} \mathrm{C}$ and the BLT increases almost linearly from 20 to $\sim 60 \mathrm{~m}$. The second region corresponds to the $10-20^{\circ}$ zonal band located west of the moving zonal SSS front. Interestingly, hot spots in $\mathrm{SST}\left(>29^{\circ} \mathrm{C}\right)$ mostly occur in the presence of a thick $(>20 \mathrm{~m}) \mathrm{BL}$. However, noteworthy is the fact that the standard deviation of SST ranges within approximately 0.5 and $1{ }^{\circ} \mathrm{C}$ in this second region, indicating that no simple universal relationship exists between the occurrence of a BL thicker than $20 \mathrm{~m}$ and hot spots in SST. Differentiating El Niño and La Niña events in Figures 8a and $8 \mathrm{~b}$ was not conclusive for determining a possible signature for the two contrasted situations.

\section{Possible Mechanisms for BL Formation, Growth, and Erosion}

[23] Previous studies have shown that the mechanisms responsible for changes in the BLT in the WP are complex and interrelated [e.g., Lukas and Lindstrom, 1991; Vialard and Delecluse, 1998a, 1998b]. Among those studies, the dynamics of BL formation, growth, and erosion were discussed and illustrated by Cronin and McPhaden [2002, equations (2), (3), and (4) and Figure 1]. Cronin and McPhaden [2002] showed that the BL could chiefly result from (1) heavy rainfall, especially (but not only) under light wind conditions; (2) horizontal advection of a remote BL; (3) the tilting of near-vertical salinity contours, requiring vertical shear in horizontal currents; and (4) the vertical stretching of the upper water column, assuming the preexistence of a BL. In the paragraphs that follow we discuss these four mechanisms. A rigorous quantitative analysis of these processes would require information on the fourdimensional (4-D) structure of temperature, salinity, and currents in the upper ocean; and information on the threedimensional (3-D) structure of local surface forcing in the atmosphere. Such an analysis was not possible with our limited, although unique, observational data sets. However, a qualitative analysis is instructive in this section in order to provide guidance for assessing the role of these processes as benchmarks for model studies.

\subsection{Precipitation, Wind, and the $B L$}

[24] Rainfall can cause a BL to form by freshening the near surface layer which then forms a vertical salinity gradient in the isothermal layer (in the absence of vertical mixing and surface heating). As was presented for $\partial S / \partial x$ and SST, ensemble relationships between precipitation $(\mathrm{P})$ and the wind stress modulus $(|\tau|$, a proxy for vertical mixing) versus the BLT are presented in Figure 9. The correlation coefficient between the bin-averaged $\mathrm{P}$ and the BLT for $1 \mathrm{~m} \mathrm{BLT}$ bins was $\mathrm{R}=0.95$, and the one between the bin-averaged $|\tau|$ and the BLT was $\mathrm{R}=-0.83$. The correlations indicate the general tendency for a thick BL to be associated with a heavy precipitation regime and a small wind stress modulus, that are favorable for generating lowsalinity near-surface waters and for maintaining the resulting salt-stratified isothermal layer, respectively. As an example, a BL thicker than $\sim 20 \mathrm{~m}$ mainly occurs during a heavy rainfall regime $\left(\mathrm{P}>5 \mathrm{~mm} \mathrm{~d}^{-1}\right)$ and a small wind stress modulus $(|\tau|<0.05 \mathrm{~Pa})$. Using only easterly or westerly winds in Figure 9b did not change our results significantly. However, as noted for the SST versus BLT relationship, the $\mathrm{P}$ versus BLT relationship is not quite robust given the magnitude of the standard deviation in $\mathrm{P}$ (of the order of 3-4 $\mathrm{mm} \mathrm{d}^{-1}$ ). A similar comment applies for wind stress, with the standard deviation of the wind stress modulus reaching $\sim 50 \%$ of the mean for a BL thicker than $20 \mathrm{~m}$. The last feature partly reflects that an energetic wind stress modulus may at times favor BL formation, as observed during westerly wind bursts [Cronin and McPhaden, 2002].

[25] Figure 10 further shows that the area of maximum $P$ $\left(>6 \mathrm{~mm} \mathrm{~d}^{-1}\right)$ nicely coincides with the area of maximum BLT $(>20 \mathrm{~m})$, as well as with the area of warmest SST $\left(>29.5^{\circ} \mathrm{C}\right.$; Figure $\left.6 \mathrm{~b}\right)$ that is located approximately $10-20^{\circ}$ in longitude to the west of the moving SSS front. To focus in on this region and to filter out the effect of coincidental zonal displacements of warm SSTs, heavy Ps, and thick BLs, we computed the correlation between bin-averaged $\mathrm{P}$ and BLT in a moving $10^{\circ}$ zonal band located west of the SSS front. The correlation was $\mathrm{R}=0.52$, indicating that the good relationship between $\mathrm{P}$ and BLT still applies in this region. Unfortunately, whether or not this could be inter- 

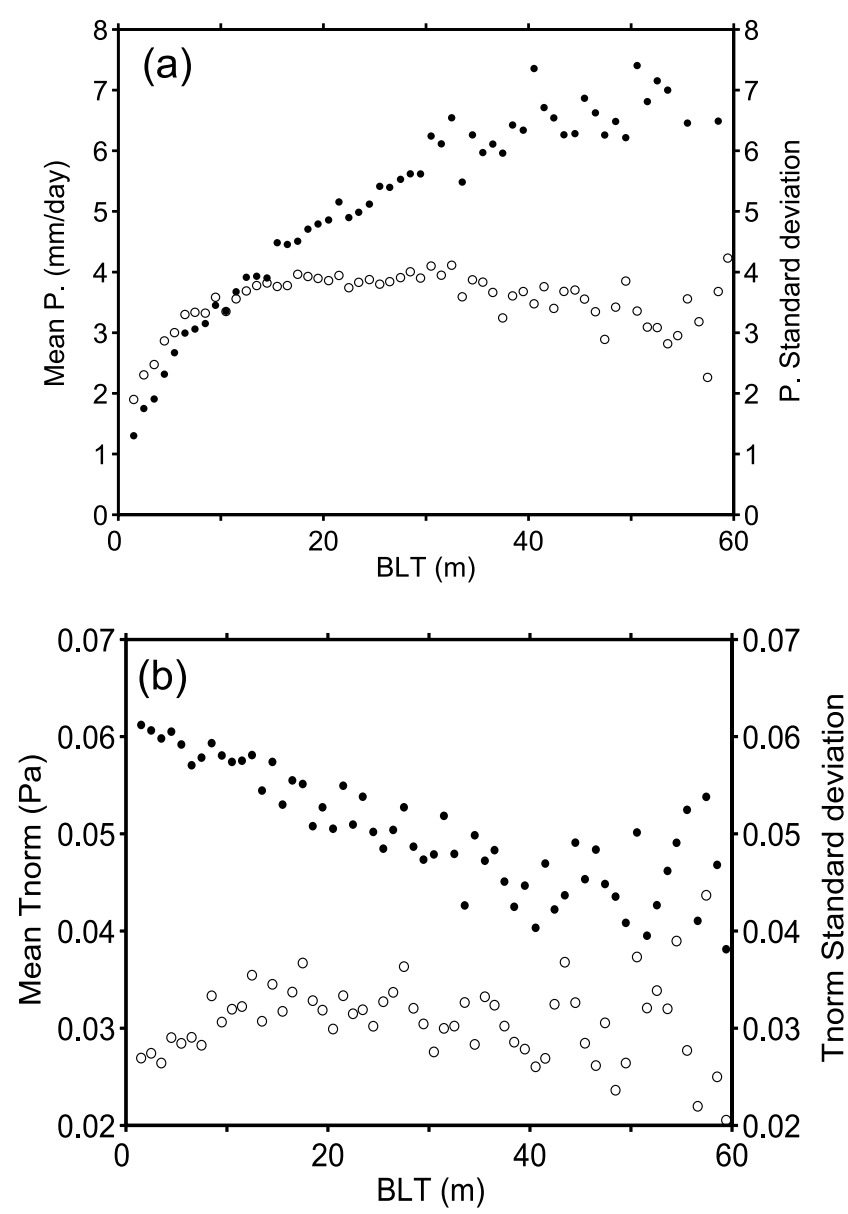

Figure 9. Bin-averaged (a) precipitation (solid circles, mm $\mathrm{d}^{-1}$ ) and (b) surface wind stress modulus (solid circles, $\mathrm{Pa}$ ), as a function of barrier layer thickness (BLT, m), for $1 \mathrm{~m}$ BLT bins. Also shown are the corresponding standard deviations (open circles) scaled on the right vertical axes. The population of the bins is shown in Figure $4 \mathrm{~b}$.

preted as a sign that heavy Ps induced thick BLs, or as a sign that thick BLs induced warm SSTs, and in turn heavy Ps could not be determined with observations. As stated above, the related climatic implications will be discussed in section 5 .

\subsection{Horizontal Advection and BL}

[26] Horizontal advection can cause a BL to form in a region through advection of a vertical salinity gradient in an isothermal layer (the term $U . \nabla \mathrm{S}_{\mathrm{z}}$ in the paper by Cronin and McPhaden [2002]). In the absence of 4-D information for $\mathrm{U}$, we only computed the surface zonal $\left(\mathrm{u}_{\mathrm{g}}^{\prime} \partial S / \partial x\right)$ and meridional $\left(\mathrm{v}_{\mathrm{g}}^{\prime} \partial \mathrm{S} / \partial \mathrm{y}\right)$ salt advection. The anomalous surface geostrophic currents $\left(\mathrm{u}_{\mathrm{g}}^{\prime}\right.$ and $\left.\mathrm{v}_{\mathrm{g}}^{\prime}\right)$ were derived from altimetry [see Bosc and Delcroix, 2008], and horizontal SSS gradients $(\partial S / \partial x$ and $\partial S / \partial \mathrm{y})$ were derived from centered differencing schemes. Meridional salt advection was not considered here since it is one order of magnitude smaller than zonal salt advection (not shown). The evolution of $\mathrm{u}_{\mathrm{g}}^{\prime}$ $\partial S / \partial x$ is shown in Figure 11, together with the position of the zonal salinity front $(\max \partial S / \partial x)$. Recall that a thick BL and a vertical salinity gradient $\left(\mathrm{S}_{\mathrm{z}}\right)$ in an isothermal layer appears in a zonal band extending $10-20^{\circ}$ in longitude to the west of the front (Figure 6d). Figure 11 indicates that the maximum in positive values for $\mathrm{u}_{\mathrm{g}}^{\prime} \partial S / \partial x$ tends to occur within and during the eastward displacement of the zonal SSS front. Such a maximum occurred during mid-2001, by the end of 2001, during most of 2002, mid-2003, the first half of 2004, mid-2005, and the second half of 2006 when a thick BL was also present. Hence, the time/space concurrence suggests that horizontal advection plays a role in generating a thick BL $(>15-25 \mathrm{~m})$, and bringing a vertical salinity gradient, only during eastward displacements of the WP. Unfortunately, a computation could not be performed in subsurface layers to ensure that this surface advection is part of the advection process involved in the generation of the BL.

\subsection{Vertical Shear in the Zonal Current and the BL}

[27] Vertically sheared horizontal flows advecting horizontal salinity gradients within an isothermal layer can also cause a BL to form in a region (the term $\mathrm{U}_{\mathrm{z}} \cdot \nabla \mathrm{S}$ in the paper by Cronin and McPhaden [2002]). The vertical structure of horizontal currents is not available at the basin scale. However, vertical structure can be obtained with a vertical resolution of $5 \mathrm{~m}$ from acoustic Doppler current profiler

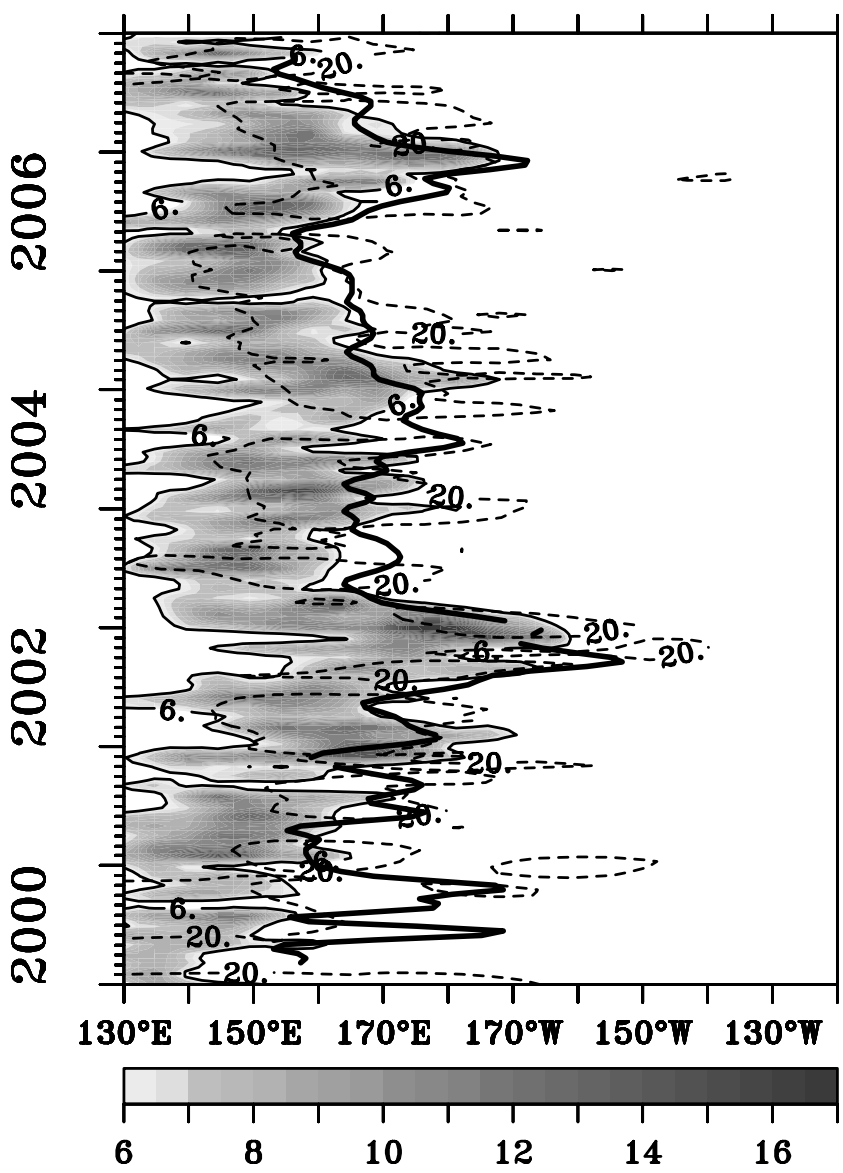

Figure 10. Longitude-time distribution of $2^{\circ} \mathrm{N}$ to $2^{\circ} \mathrm{S}$ averaged precipitation $\left(\mathrm{mm} \mathrm{d}^{-1}\right)$; only values in excess of $6 \mathrm{~mm} \mathrm{~d}^{-1}$ are reported. The heavy black lines represent the maximum $\partial S / \partial x$ (as in Figure 6), and dashed lines denote the $20 \mathrm{~m}$ BLT. 


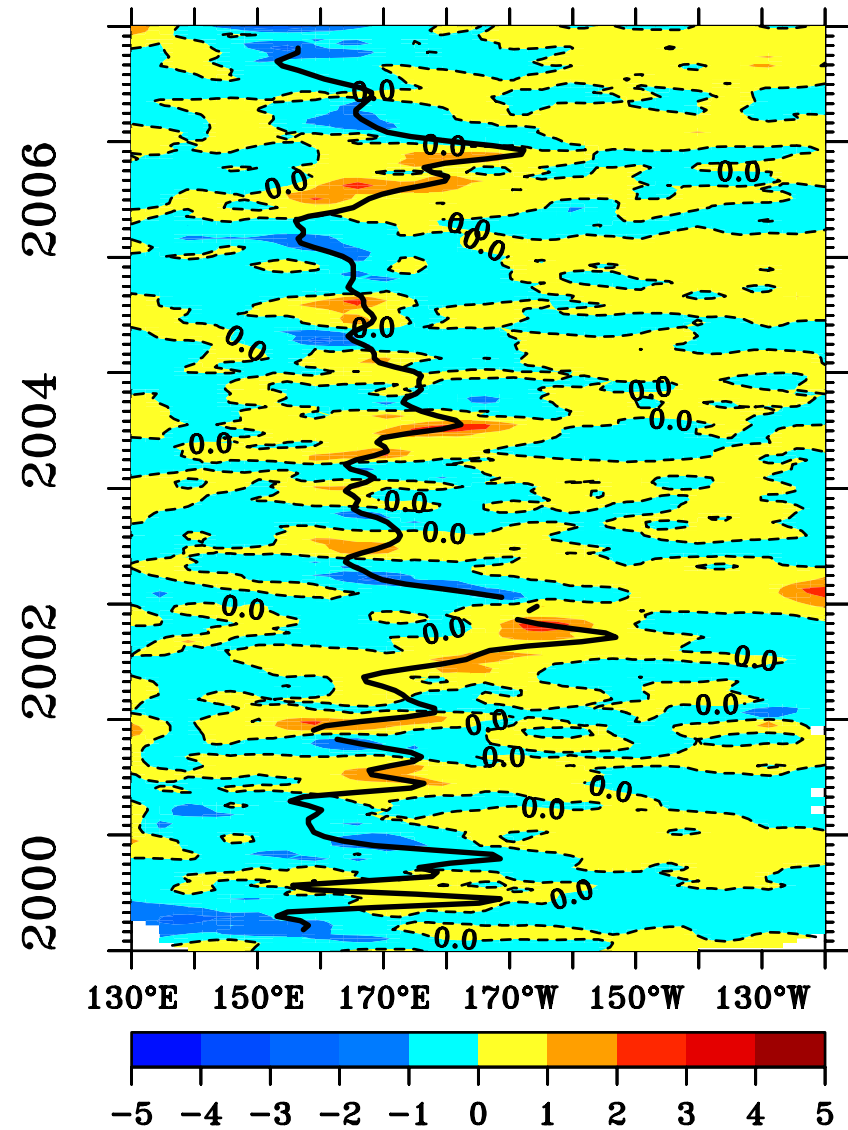

Figure 11. Longitude-time distribution of $2^{\circ} \mathrm{N}$ to $2^{\circ} \mathrm{S}$ averaged surface zonal salt advection $\left(\mathrm{u}_{\mathrm{g}}^{\prime} \partial S / \partial x, 10^{-7} \mathrm{~s}^{-1}\right)$. The heavy black lines represent the maximum $\partial S / \partial x$, as in Figure 6.

(ADCP) measurements collected from two TAO mooring sites along the equator at $165^{\circ} \mathrm{E}$ and $170^{\circ} \mathrm{W}$. The infrequent ADCP data for the upper 20-35 m (i.e., within the MLD) were filled in with altimeter-derived surface geostrophic currents that are known to compare quite well with in situ data for overlapping periods [see Bosc and Delcroix, 2008]. Figure 12 shows the depth-time plots of the zonal current shears $(\partial \mathrm{U} / \partial \mathrm{z})$ calculated in the upper $120 \mathrm{~m}$ for these two sites during 2000-2007 (data were not yet available for 2007 at the time of writing). For comparison, depths of the $0.5^{\circ} \mathrm{N}$ to $0.5^{\circ} \mathrm{S}$ averaged MLD and ILD denoting the vertical position and thickness of the BL were overplotted at the same longitudes. At $0-165^{\circ} \mathrm{E}, \partial \mathrm{U} / \partial \mathrm{z}$ was negative most of the time within the BL (i.e., in between the ILD and the MLD) when the local BL was rather thick; conversely, $\partial \mathrm{U} / \partial \mathrm{z}$ was positive in 2000 and in the first few months of 2003 and 2006 when the local BL was rather thin (Figure $6 \mathrm{~d}$ ). Yet, at $0-170^{\circ} \mathrm{W}, \partial \mathrm{U} / \partial \mathrm{z}$ was negative from mid-2002 to early 2003 and, to a lesser extent, in early 2005 when the local BL was rather thick. Additionally, $\partial \mathrm{U} / \partial \mathrm{z}$ was positive during the remaining time period when the $\mathrm{BL}$ was quasi-nonexistent (Figure 6d). Within the BL, at $0-165^{\circ} \mathrm{E}$, the correlation between bin-averaged $\partial \mathrm{U} / \partial \mathrm{z}$ and the BLT was $\mathrm{R}=0.6$ for the entire time period. (The correlation is not discussed here from 0 to $170^{\circ} \mathrm{W}$ since it was not significant because of the rare occurrence of the $\mathrm{BL}$ at this location). Differentiating eastward and westward currents in Figure 12 was not conclusive for a possible signature for the two contrasting situations. Hence, for both tested longitudes, there was a hint of negative vertical shear in zonal currents, as well as for positive zonal surface salinity gradients $(\partial S / \partial x$, see Figure 6c) to coexist with a thick BL. By assuming that $\partial S / \partial x$ was representative of the zonal salinity gradient in the upper $40-60 \mathrm{~m}$, these two conditions, $\partial \mathrm{U} / \partial \mathrm{z}<0$ and $\partial S / \partial x$ $>0$, corresponded to the tilting mechanism for BL formation as discussed in previous publications [Roemmich et al., 1994; Vialard and Delecluse, 1998b; Cronin and McPhaden, 2002]. However, with our observational data we could not discriminate whether the negative vertical shear $(\partial \mathrm{U} / \partial \mathrm{z}<0)$ appearing at times was a cause or a consequence of the thick $\mathrm{BL}$, as discussed in section 4.2.

\subsection{Vertical Stretching and the BL}

[28] As noted above when discussing Figure 4a, a thickening of the BL can result from a deepening of the ILD, a shoaling of the MLD, and/or a differential deepening of the ILD and MLD (in that case, related to the term $\mathrm{w}_{\mathrm{z}} \mathrm{S}_{\mathrm{z}}$ in the paper by Cronin and McPhaden [2002]). A few previous studies that have examined the tropical Pacific BL have suggested that changes in the BLT could result from

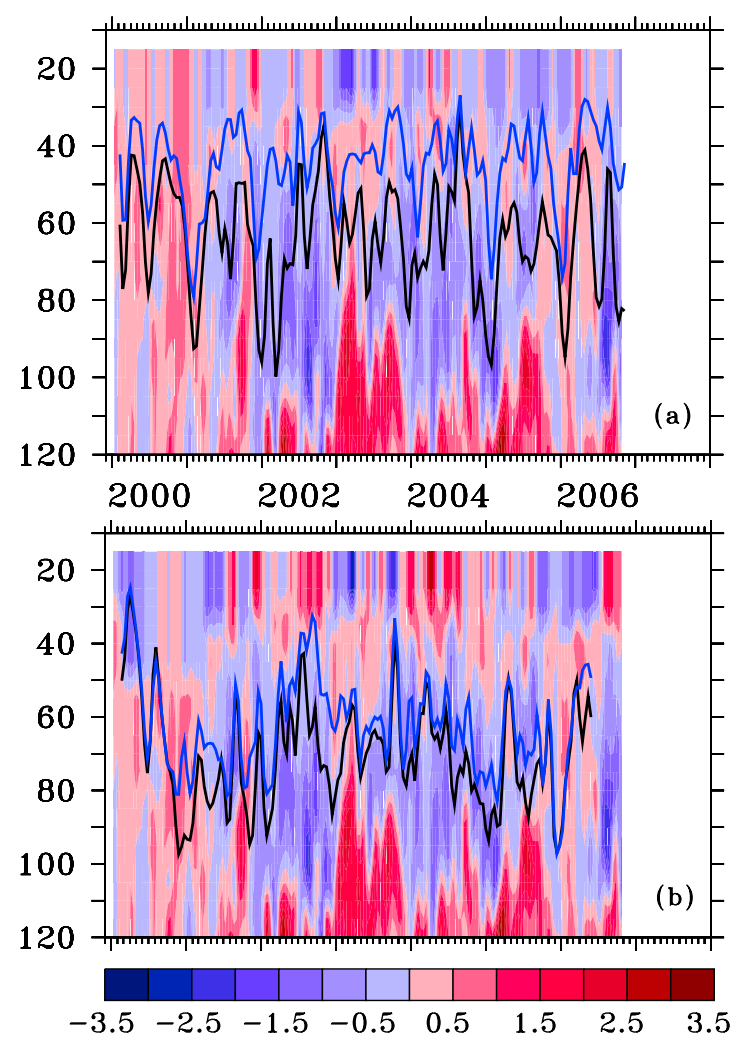

Figure 12. Time-depth distribution of the zonal current vertical gradient $\left(\partial \mathrm{U} / \partial \mathrm{z}, 10^{-2} \mathrm{~s}^{-1}\right)$, derived from acoustic Doppler current profiler measurements collected at the (a) $0-165^{\circ} \mathrm{E}$ and (b) $0-170^{\circ} \mathrm{W}$ TAO mooring sites. Negative values denote a decrease of zonal current with depth. A 1.5 month Hanning filter was applied for clarity. The blue line represents the mixed layer depth, and the black line is the isothermal layer depth. 

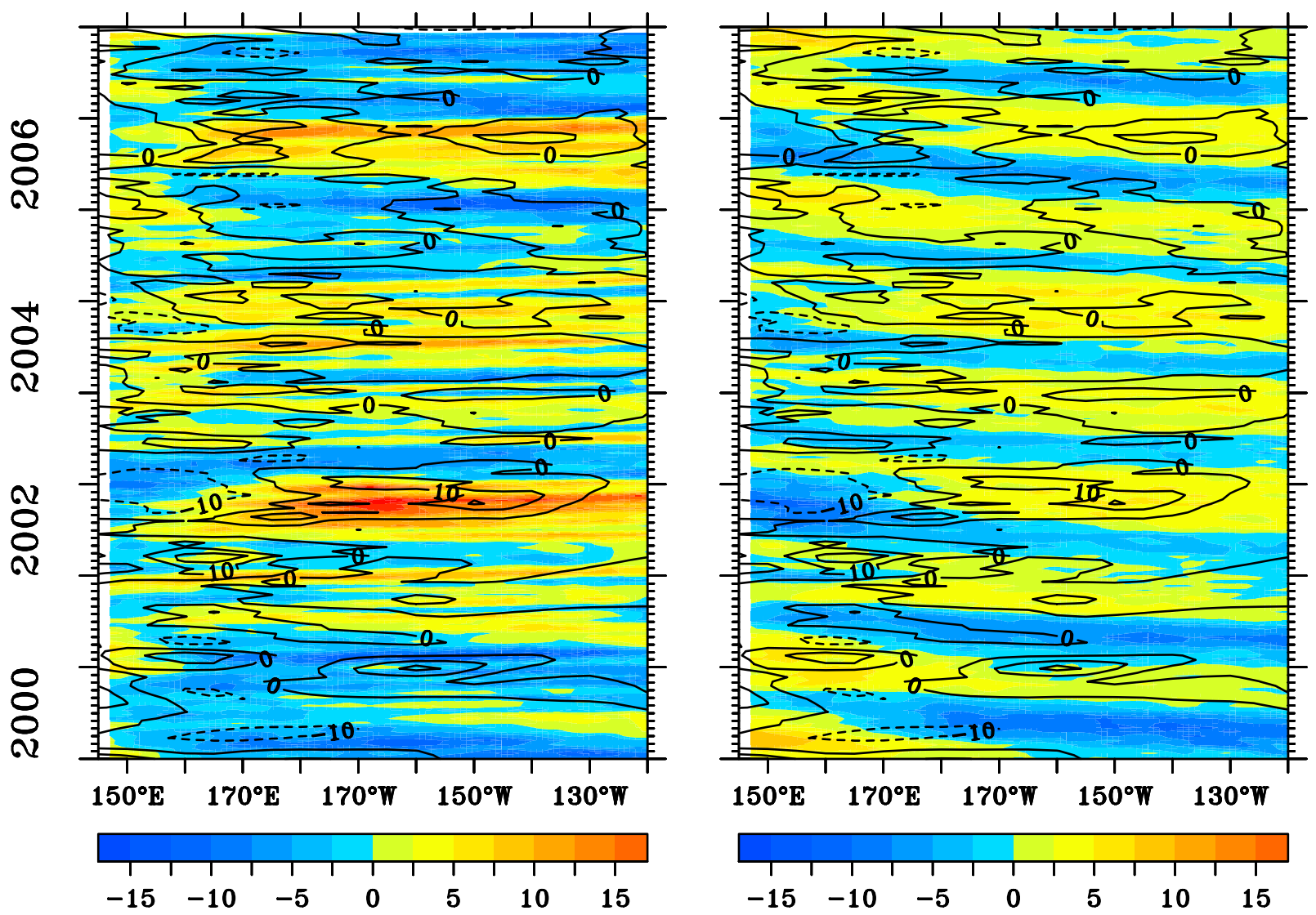

Figure 13. Longitude-time distribution of the $2^{\circ} \mathrm{N}$ to $2^{\circ} \mathrm{S}$ averaged sea level anomalies (cm) associated with the (left) first baroclinic Kelvin and (right) first meridional mode Rossby waves. Positive values denote downwelling equatorial waves. Black contours in Figures 13 (left) and 13 (right) show the $2^{\circ} \mathrm{N}$ to $2^{\circ} \mathrm{S}$ averaged barrier layer thickness anomalies (m). All of the anomalies are given relative to the $2000-$ 2007 period.

equatorial waves acting remotely on the MLD and the ILD [Shinoda and Lukas, 1995; Vialard and Delecluse, 1998b; Delcroix and McPhaden, 2002; Cronin and McPhaden, 2002]. One possible explanation is that the amplitude of the vertical velocity associated with long equatorial waves increases downward in the upper ocean [Eriksen, 1982], meaning that the related vertical displacements are larger at the ILD than at the MLD, which could favor a thickening of the BL (in the case of downward velocity). To further understand this possible process, Figure 13 presents longitude-time plots for the $2^{\circ} \mathrm{N}$ to $2^{\circ} \mathrm{S}$ averaged contribution of the first baroclinic Kelvin waves and the first meridional mode $(\mathrm{m}=1)$ Rossby waves of the SLA, as derived by Bosc and Delcroix [2008]. Since these plots denote sea level anomalies, the notion of upwelling or downwelling waves is a function of the chosen reference time period (2000-2007 in our case). For comparison purposes, we computed the anomalous BLTs relative to the same reference time period (see Figure 5 to get the mean BLT), and the values were superimposed on Figure 13. As seen in Figure 13, there is a clear tendency for downwelling (SLA $>0$ ) Kelvin and Rossby waves to coincide with positive anomalous BLTs. In particular, this occurred east of approximately $170^{\circ} \mathrm{E}$ during the second half of 2002, 2004, and 2006 for downwelling Kelvin waves, and roughly every year for westward propagating downwelling Rossby waves. There- fore, the BL appeared to be thicker than average in the presence of downwelling Kelvin and Rossby waves, and thinner than average for upwelling waves. Noting that downwelling Kelvin waves are associated with eastward and downwelling Rossby waves with westward current anomalies, it is unlikely that the related thickening of the BL would result from zonal advection rather than vertical stretching.

[29] To compare the relative effects of Kelvin and Rossby waves, Figure 14 presents the ensemble relationships between these equatorial waves and an anomalous BLT, following the procedure described for Figures 8-9. As can been inferred from Figure 13, a steeper slope for Kelvin rather than for Rossby waves indicates that the BLT is much more affected by Kelvin waves. The steeper slope likely results from the SLA meridional structure (proportional to the vertical displacements) of Kelvin waves which have a maximum at the equator (and so within $2^{\circ} \mathrm{N}$ to $2^{\circ} \mathrm{S}$ ), as compared to the $m=1$ Rossby wave structure which is near zero at the equator and presents two symmetrical maxima near $4^{\circ}$ latitude [e.g., Delcroix et al., 1994].

\section{Conclusion and Discussion}

[30] The variability of the barrier layer (BL) in the western Pacific warm pool was investigated from 2000 to 

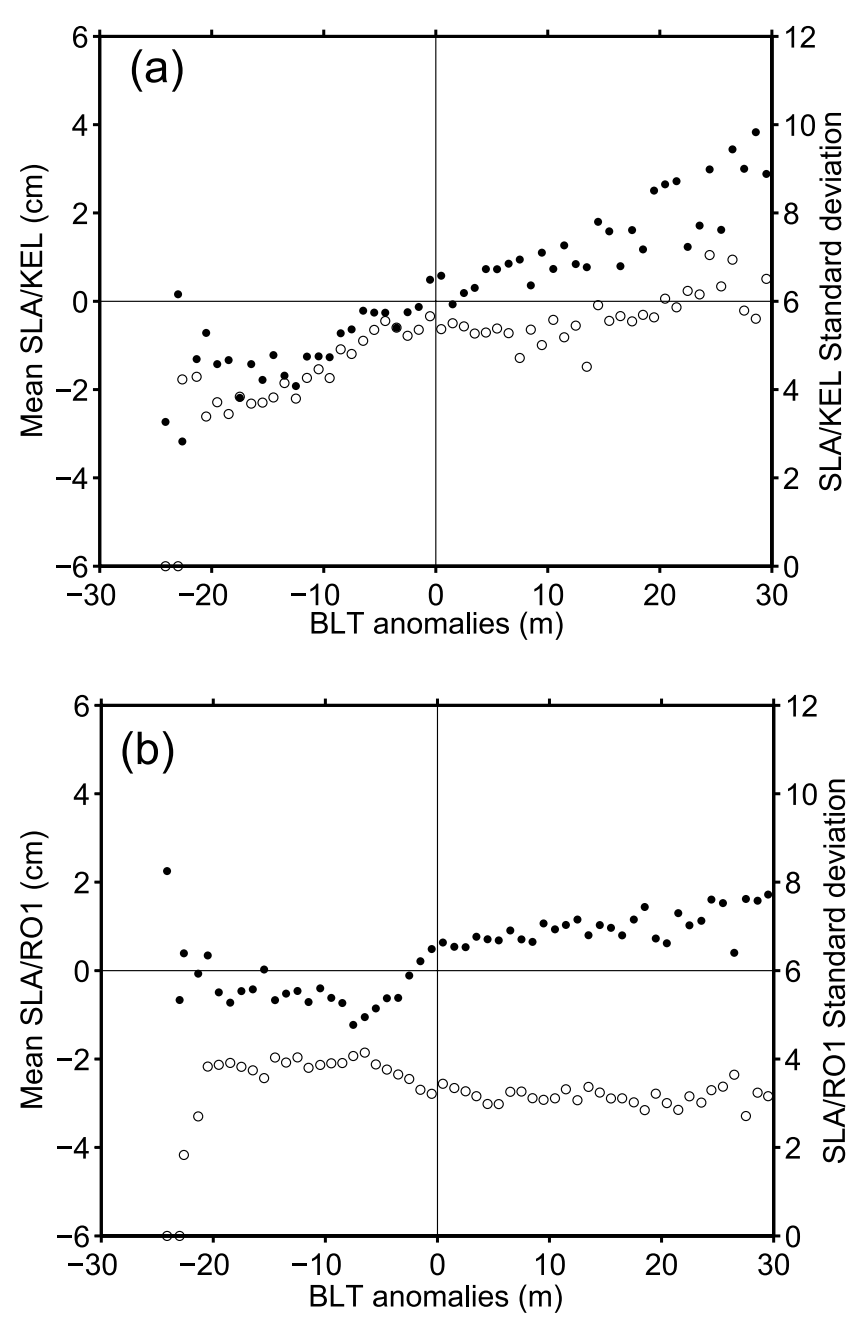

Figure 14. Bin-averaged sea level anomalies associated with the first baroclinic (a) Kelvin (solid circles, $\mathrm{cm}$ ) and (b) first meridional mode Rossby (solid circles, $\mathrm{cm}$ ) waves as a function of barrier layer thickness anomalies for $1 \mathrm{~m}$ BLT bins. Also shown are the corresponding standard deviations (open circles), scaled on the right vertical axes.

2007, which encompassed a period of moderate El Niño and La Niña events. The investigation was performed using the unprecedented availability of concurrent temperature and salinity profiles provided by Argo floats. We derived basic statistics for the BL; analyzed the covariability of the BL against SSS, SST, a zonal salinity gradient at the eastern edge of the warm pool, and ENSO; and attempted to assess the contribution of the mechanisms responsible for its observed changes in space and time.

[31] Our results indicate that a region of thick $(>15-25 \mathrm{~m})$ $\mathrm{BL}$ robustly occurs in the equatorial band in the western Pacific warm pool. The region extends over $\sim 10-20^{\circ}$ in longitude to the west of the maximum zonal SSS gradient $(\partial S / \partial x)$, featuring the eastern edge of the warm pool, and moves eastward during El Niño events and westward during La Niña events over more than $6000 \mathrm{~km}$. Such a region is crucial for establishing the necessary ocean-atmosphere interactions in the advective/reflective conceptual model accounting for the oscillatory nature of ENSO [Picaut et al., 1997]. The thickness of the BL appears to be tightly related to the strength of the maximum $\partial S / \partial x$, indicating that present in situ and future satellite-derived SSS measurements may provide relevant information both on the position and thickness of the BL. Interestingly, our calculations further indicate that the presence of BLs thicker than $\sim 20 \mathrm{~m}$ are quasi-permanently associated with the occurrence of SSTs warmer than $\sim 29-29.5^{\circ} \mathrm{C}$, a value that has been shown to be related to a maximum atmospheric convection [Waliser and Graham, 1993]. The occurrence of a thick BL then appears as a crucial ingredient for warm pool oceanicatmospheric interactions, which are known to affect the atmospheric circulation at the global scale [Hoerling and Kumar, 2003].

[32] The mechanisms responsible for BL formation, growth, and erosion were discussed qualitatively to improve our understanding of BL formation from in situ measurements and provide benchmarks for model studies. As could have been surmised from a synthesis of previous results, at least partially, we have confirmed that understanding the origin and variability of the BL in the WP is extremely complex, since it involves the contribution of different interrelated mechanisms. On the basis of complementary observations, we have shown statistically that the occurrence of a thick $(>15-25 \mathrm{~m}) \mathrm{BL}$ is highly related to the presence of heavy rainfall, light winds, eastward advection of low SSS (especially during El Niño periods), and zonal current negative vertical shears. We further demonstrated that the $\mathrm{BL}$ is most likely modulated through vertical stretching of the upper water column associated with remotely forced equatorial Kelvin and (to a lesser extent) Rossby waves. However, it should be emphasized that no unique and dominant mechanism among those we identified explains the full variability of the BL during the entire period from 2000 to 2007.

[33] Some key issues still remain undocumented and/or unresolved. First, we established clear evidence for strong relationships between the time/space coincidence of a thick BL $(>15-25 \mathrm{~m})$, heavy P $\left(>6 \mathrm{~mm} \mathrm{~d}^{-1}\right)$, and warm SST $\left(>29.5^{\circ} \mathrm{C}\right)$. One possibility for these relationships is that a thick BL favors the maintenance of warm SST (by cutting off entrainment cooling), which provides the potential for organized atmospheric convection and leads to an increase in $\mathrm{P}$ which favors a thick BL (by inducing low near-surface salinity). Another possibility is that an area of warm SSTs and hence heavy Ps follows the front displacements driven by zonal advection, and that the BL does not really have an active role. This would not be consistent with model simulations that have established the key role of BL for warm SST [Vialard and Delecluse, 1998b]. Clearly, the driving process (if any) in these coupled interactions, has to be identified, possibly with the help of coupled models as discussed by Maes et al. [2002]. Second, we also showed tight relationships between the vertical shear in zonal currents and BL formation. Vialard and Delecluse [1998b] suggested that current shear is due to the presence of the BL which reduces the penetration depth of the wind momentum. On the other hand, Roemmich et al. [1994] and Cronin and McPhaden [2002] suggested that the $\mathrm{BL}$ is due to the occurrence of current shear which favors the so-called tilting/shearing mechanism that is likely a complex process worth further investigation. Important to note is that each 
mechanism could be relevant for different locations and different time periods. Third, the quasi-permanence of a BL thicker than $15-25 \mathrm{~m}$, west of approximately $170^{\circ} \mathrm{W}$ and spanning approximately $10-20^{\circ}$ in longitude during $2000-$ 2007, represents a feature that deserved attention. Fujii and Kamachi [2003] and Maes et al. [2005] reported such a quasi-permanent BL to the west of the front position during 1993-2002. However, both studies analyzed the BLT using a salinity field that was reconstructed with an indirect approach. In contrast, such a permanence was not observed from 1978 to 1994 [Ando and McPhaden, 1997] or from 1992 to 2000 [Delcroix and McPhaden, 2002]. Again as for the studies by Fujii and Kamachi [2003] and Maes et al. [2005] both studies relied on a rather poor time/space coverage in data (mainly CTD profiles). In our study, the $\mathrm{BL}$ was found to be quasi-permanent for both El Niño and La Niña events. Therefore, it is difficult to determine whether or not a thick BL is a prerequisite for El Niño. As a result, further studies should be conducted to establish the precise role of the BL in the ENSO cycle. Finally, the time/space coincidence of a thick BL and a warm SST is remarkable. Determining the actual role of the $\mathrm{BL}$ for this phenomenon during 2000-2007 would require an explicit evaluation of all of the terms involved in the mixed layer heat budget, as has been done in studies based on Ocean General Circulation Models (see, for example, Vialard et al. [2001] and references therein). Whatever the final results, they suggest, at this stage, that the time/space coincidence should be included in model simulations aimed at reproducing realistic warm pool SSTs.

[34] Acknowledgments. Argo data were collected and made freely available through the International Argo Project and the national initiatives that contributed to it (http://www.argo.net and http://www.coriolis.eu. org). We also acknowledge the Sea Surface Salinity Observation Service (http://www.legos.obs-mip.fr/observations/sss/), the TAO Project Office (http://www.pmel.noaa.gov/tao/), the Climate Prediction Center (http:// www.cpc.ncep.noaa.gov/products/global precip/html/web.html), and the National Oceanographic Data Center (http://www.nodc.noaa.gov/OC5/ indprod.html) for providing free and open access through the World Wide Web to the data we used in this paper. We had useful discussions with S. Cravatte and F. Durand during the course of the study. Comments from M. Cronin and J. Vialard were helpful in improving the paper. Part of this work was supported by a grant from the French Groupe Mission Mercator Coriolis. C. Bosc was further supported by a grant from the French Ministére de l'Education Nationale, de l'Enseignement Supérieur et de la Recherche during her Ph.D. thesis.

\section{References}

Adler, R. F., et al. (2003), The version 2 Global Precipitation Climatology Project (GPCP) monthly precipitation analysis (1979-present), J. Hydrometeorol., 4, 1147-1167, doi:10.1175/1525-7541(2003)004<1147: TVGPCP $>2.0 . \mathrm{CO} ; 2$

Anderson, S. P., R. A. Weller, and R. Lukas (1996), Surface buoyancy forcing and the mixed layer in the western Pacific warm pool: Observation and one-dimensional model results, J. Clim., 9, 3056-3085, doi:10.1175/1520-0442(1996)009<3056:SBFATM >2.0.CO;2.

Ando, K., and M. J. McPhaden (1997), Variability of surface layer hydrography in the tropical Pacific Ocean, J. Geophys. Res., 102, 23,063-23,078, doi:10.1029/97JC01443.

Bentamy, A., P. Queffeulou, Y. Quilfen, and K. Katsaros (1999), Ocean surface wind fields estimated from satellite active and passive microwave instruments, IEEE Trans. Geosci. Remote Sens., 37, 2469-2486, doi:10.1109/36.789643

Bosc, C. (2008), Variabilité du volume d'eau chaude et de la couche barrière de sel dans l'Océan Pacifique équatorial à l'échelle interannuelle (ENSO), Ph.D. thesis, 146 pp., Univ. Paul Sabatier, Toulouse, France.

Bosc, C., and T. Delcroix (2008), Observed equatorial Rossby waves and ENSO-related warm water volume changes in the equatorial Pacific Ocean, J. Geophys. Res., 113, C06003, doi:10.1029/2007JC004613.
Cronin, M. F., and M. J. McPhaden (2002), Barrier layer formation during westerly wind bursts, J. Geophys. Res., 107(C12), 8020, doi:10.1029/ 2001JC001171.

de Boyer Montégut, C., G. Madec, A. S. Fischer, A. Lazar, and D. Ludicone (2004), Mixed layer depth over the global ocean: An examination of profile data and a profile-based climatology, J. Geophys. Res., 109, C12003, doi:10.1029/2004JC002378.

de Boyer Montégut, C., J. Mignot, A. Lazar, and S. Cravatte (2007), Control of salinity on the mixed layer depth in the world ocean: 1 . General description, J. Geophys. Res., 112, C06011, doi:10.1029/2006JC003953.

Delcroix, T., and M. J. McPhaden (2002), Interannual sea surface salinity and temperature changes in the western Pacific warm pool during $1992-$ 2000, J. Geophys. Res., 107(C12), 8002, doi:10.1029/2001JC000862.

Delcroix, T., and J. Picaut (1998), Zonal displacement of the western equatorial Pacific "fresh pool", J. Geophys. Res., 103, 1087-1098, doi:10.1029/97JC01912.

Delcroix, T., G. Eldin, M.-H. Radenac, J. Toole, and E. Firing (1992), Variation of the western equatorial Pacific Ocean, 1986-1988, J. Geophys. Res., 97, 5423-5445, doi:10.1029/92JC00127.

Delcroix, T., J. P. Boulanger, F. Masia, and C. Menkes (1994), GEOSATderived sea level and surface current anomalies in the equatorial Pacific during the 1986-1989 El Nino and La Nina, J. Geophys. Res., 99, 25,093-25,107, doi:10.1029/94JC02138.

Delcroix, T., S. Cravatte, and M. J. McPhaden (2007), Decadal variations and trends in tropical Pacific sea surface salinity since 1970, J. Geophys. Res., 112, C03012, doi:10.1029/2006JC003801.

Eldin, G., M. Rodier, and M.-H. Radenac (1997), Physical and nutrient variability in the upper equatorial Pacific associated with westerly wind forcing and wave activity in October 1994, Deep Sea Res., Part II, 44, $1783-1800$

Eldin, G., T. Delcroix, and M. Rodier (2004), The frontal area at the eastern edge of the western equatorial Pacific warm pool in April 2001, J. Geophys. Res., 109, C07006, doi:10.1029/2003JC002088.

Eriksen, C. (1982), Equatorial wave vertical modes observed in a western Pacific island array, J. Phys. Oceanogr., 12, 1206-1227, doi:10.1175/ 1520-0485(1982)012<1206:EWVMOI $>2.0 . \mathrm{CO} ; 2$

Fujii, Y., and M. Kamachi (2003), Three-dimensional analysis of temperature and salinity in the equatorial Pacific using a variational method with vertical coupled temperature-salinity empirical orthogonal function modes, J. Geophys. Res., 108(C9), 3297, doi:10.1029/2002JC001745.

Gill, A. E. (1983), An estimation of sea-level and surface-current anomalies during the 1972 El Niño and consequent thermal effects, J. Phys. Oceanogr., 13, 586-606, doi:10.1175/1520-0485(1983)013<0586:AEOSLA > 2.0.CO;2

Hoerling, M., and A. Kumar (2003), The perfect ocean for drought, Science, 299, 691-694, doi:10.1126/science.1079053.

Kara, A., P. Rochford, and H. Hurlburt (2000), An optimal definition for ocean mixed layer, J. Geophys. Res., 105, 16,803-16,821, doi:10.1029/ 2000JC900072.

Kerr, Y., P. Waldteufel, J. P. Wigneron, J. M. Martinuzzi, J. Font, and M. Berger (2001), Soil moisture retrieval from space: The Soil Moisture and Ocean Salinity (SMOS) mission, IEEE Trans. Geosci. Remote Sens., 39, 1729-1735, doi:10.1109/36.942551.

Kuroda, Y., and M. J. McPhaden (1993), Variability in the western equatorial Pacific Ocean during JAPACS cruises in 1989 and 1990, J. Geophys. Res., 98, 4747-4759, doi:10.1029/92JC02684.

Le Borgne, R., R. Barber, T. Delcroix, H. Inoue, D. Mackey, and M. Rodier (2002), Pacific warm pool and divergence: Temporal and zonal variations on the equator and their effects on the biological pump, Deep Sea Res., Part II, 49, 2471 - 2512, doi:10.1016/S0967-0645(02)00045-0.

Levitus, S. (1982), Climatological atlas of the world ocean, Prof. Pap. 13, 173 pp., NOAA, Silver Spring, Md.

Lindstrom, E., R. Lukas, R. Fine, E. Firing, S. Godfrey, G. Meyers, and M. Tsuchiya (1987), The western equatorial Pacific Ocean circulation study, Nature, 330, 533-537, doi:10.1038/330533a0

Lukas, R., and E. Lindstrom (1991), The mixed layer of the western equatorial Pacific Ocean, J. Geophys. Res., 96, 3343-3357.

Maes, C. (2000), Salinity variability in the equatorial Pacific Ocean during the 1993-98 period, Geophys. Res. Lett., 27, 1659-1662, doi:10.1029/ 1999GL011261.

Maes, C. (2008), On the ocean salinity stratification observed at the eastern edge of the equatorial Pacific warm pool, J. Geophys. Res., 113, C03027, doi:10.1029/2007JC004297.

Maes, C., and D. Behringer (2000), Using satellite-derived sea level and temperature profiles for determining the salinity variability: A new approach, J. Geophys. Res., 105, 8537-8548, doi:10.1029/1999JC900279.

Maes, C., P. Delecluse, and G. Madec (1997), Impact of westerly wind bursts on the warm pool of the TOGA-COARE domain in an OGCM, Clim. Dyn., 14, 55-70, doi:10.1007/s003820050208. 
Maes, C., J. Picaut, and S. Belamari (2002), Salinity barrier layer and onset of El Niño in a Pacific coupled model, Geophys. Res. Lett., 29(24), 2206 doi:10.1029/2002GL016029.

Maes, C., J. Picaut, Y. Kuroda, and K. Ando (2004), Characteristics of the convergence zone at the eastern edge of the Pacific warm pool, Geophys. Res. Lett., 31, L11304, doi:10.1029/2004GL019867.

Maes, C., J. Picaut, and S. Belamari (2005), Importance of salinity barrier layer for the buildup of El Niño, J. Clim., 18, 104-118, doi:10.1175/ JCLI-3214.1.

Maes, C., K. Ando, T. Delcroix, W. S. Kessler, M. J. McPhaden, and D. Roemmich (2006a), Observed correlation of surface salinity, temperature and barrier layer at the eastern edge of the western Pacific warm pool, Geophys. Res. Lett., 33, L06601, doi:10.1029/2005GL024772.

Maes, C., E. Kestenare, A. Ganachaud, F. Gallois, M. Rodier, D. Varillon, G. Eldin, R. Chuchla, and A. Lapetite (2006b), Rapport de la mission FRONTALIS-3 à bord du N. O. Alis du 22 Avril au 19 Mai $2005,22^{\circ} \mathrm{S}-$ $2^{\circ} \mathrm{N} / 161^{\circ} \mathrm{E}-172^{\circ} \mathrm{E}$, in Rapports de Missions, Sciences de la Mer, Océanographie Physique, Rep. 20, pp. 1-167, Int. de Rech. pour le Dev., Nouméa, New Caledonia.

McPhaden, M. J. (1995), The tropical atmosphere ocean array is completed, Bull. Am. Meteorol. Soc., 76, 739-741.

McPhaden, M. J., et al. (1998), The Tropical Ocean-Global Atmosphere observing system: A decade of progress, J. Geophys. Res., 103, 14,169-14,240, doi:10.1029/97JC02906.

Mignot, J., C. de Boyer Montegut, A. Lazar, and S. Cravatte (2007), Control of salinity on the mixed layer depth in the world ocean: 2. Tropical areas, J. Geophys. Res., 112, C10010, doi:10.1029/2006JC003954.

Millero, F. J. (1993), What is PSU?, Oceanography (Wash. D.C.), 6(3), 67.

Palmer, T. N., and D. A. Mansfield (1984), Response of two atmospheric general circulation models to sea-surface temperature anomalies in the tropical east and west Pacific, Nature, 310, 483-488, doi:10.1038/ 310483a0.

Picaut, J., and T. Delcroix (1995), Equatorial wave sequence associated with the warm pool displacement during the 1986-1989 El Niño and La Nina, J. Geophys. Res., 100, 18,393-18,408, doi:10.1029/ 95JC01358.

Picaut, J., M. Ioualalen, C. Menkes, T. Delcroix, and M. J. McPhaden (1996), Mechanism of the zonal displacements of the Pacific warm pool: Implications for ENSO, Science, 274, 1486-1489, doi:10.1126/ science.274.5292.1486.

Picaut, J., F. Masia, and Y. du Penhoat (1997), An advective-reflective conceptual model for the oscillatory nature of the ENSO, Science, 277, 663-666, doi:10.1126/science.277.5326.663.

Picaut, J., M. Ioualalen, T. Delcroix, F. Masia, R. Murtugudde, and J. Vialard (2001), The oceanic zone of convergence on the eastern edge of the Pacific warm pool: A synthesis of results and implications for ENSO and biogeochemical phenomena, J. Geophys. Res., 106, 2363-2386, doi:10.1029 2000JC900141.

Roemmich, D., and W. B. Owens (2000), The Argo Project: Global ocean observations for understanding and prediction of climate variability, Oceanography (Wash. D.C.), 13(2), 45-50.

Roemmich, D., M. Morris, W. R. Young, and J.-R. Donguy (1994), Fresh equatorial jets, J. Phys. Oceanogr., 24, 540-558, doi:10.1175/15200485(1994)024<0540:FEJ>2.0.CO;2.
Sato, K., T. Suga, and K. Hanawa (2004), Barrier layer in the North Pacific subtropical gyre, Geophys. Res. Lett., 31, L05301, doi:10.1029/ 2003GL018590

Sato, K., T. Suga, and K. Hanawa (2006), Barrier layers in the subtropical gyres of the world's oceans, Geophys. Res. Lett., 33, L08603, doi:10.1029/2005GL025631.

Shinoda, T., and R. Lukas (1995), Lagrangian mixed layer modeling of the western equatorial Pacific, J. Geophys. Res., 100, 2523-2541, doi:10.1029/94JC02486.

Sprintall, J., and M. J. McPhaden (1994), Surface layer variations observed in multiyear time series measurements from the western equatorial Pacific, J. Geophys. Res., 99, 963-979, doi:10.1029/93JC02809.

Sprintall, J., and M. Tomczak (1992), Evidence of the barrier layer in the surface layer of the tropics, J. Geophys. Res., 97, 7305-7316, doi:10.1029/92JC00407.

Sudre, J., and R. Morrow (2008), Global surface currents: A high resolution product for investigating ocean dynamics, Ocean Dyn., 58, doi:10.1007/ s10236-008-0134-9.

Tomczak, M., and J. S. Godfrey (1994), Regional Oceanography: An Introduction, 422 pp., Pergamon, New York.

Vialard, J., and P. Delecluse (1998a), An OGCM study for the TOGA decade. Part I: Role of salinity in the physics of the western Pacific fresh pool, J. Phys. Oceanogr., 28, 1071-1088, doi:10.1175/15200485(1998)028<1071:AOSFTT>2.0.CO;2.

Vialard, J., and P. Delecluse (1998b), An OGCM study for the TOGA decade. Part II: Barrier layer formation and variability, J. Phys. Oceanogr., 28, 1089-1106, doi:10.1175/1520-0485(1998)028<1089: AOSFTT $>2.0 . \mathrm{CO} ; 2$

Vialard, J., C. Menkes, J.-P. Boulanger, P. Delecluse, E. Guilyardi, and M. McPhaden (2001), A model study of the oceanic mechanisms affecting the equatorial SST during the 1997-98 El Niño, J. Phys. Oceanogr., 31, 1649-1675, doi:10.1175/1520-0485(2001)031<1649:AMSOOM >2.0. $\mathrm{CO} ; 2$.

Vialard, J., P. Delecluse, and C. Menkes (2002), A modeling study of salinity variability and its effects in the tropical Pacific Ocean during the 1993-1999 period, J. Geophys. Res., 107(C12), 8005, doi:10.1029/ 2000JC000758.

Waliser, D. E. (1996), Formation and limiting mechanisms for very high sea surface temperature: Linking the dynamics and the thermodynamics, J. Clim., 9, 161-188, doi:10.1175/1520-0442(1996)009<0161: FALMFV $>2.0 . \mathrm{CO} ; 2$

Waliser, D. E., and N. E. Graham (1993), Convective cloud systems and warm-pool sea surface temperatures: Coupled interactions and self-regulation, J. Geophys. Res., 98, 12,881-12,893, doi:10.1029/93JD00872.

Wyrtki, K. (1984), The slope of sea level along the equator during the 1982/ 1983 El Niño, J. Geophys. Res., 89, 10,419-10,424, doi:10.1029/ JC089iC06p10419.

C. Bosc and T. Delcroix, LEGOS, UMR5566, UPS, CNES, IRD, CNRS, 14 Avenue Edouard Belin, F-31400 Toulouse, France. (thierry.delcroix@ ird.fr)

C. Maes, LEGOS, UMR5566, UPS, CNES, IRD, CNRS, B.P. A5, Nouméa 98848, New Caledonia. 